\title{
Cartografia digital \\ geo-histórica: mobilidade urbana de São Paulo de I877 a 1930
}

\author{
[ Geo-historical digital cartography: the urban \\ mobility of São Paulo from I877 to I930
}

\section{Fernanda Padovesi Fonseca ${ }^{\mathrm{I}}$}

\section{Eduardo Dutenkefer ${ }^{2}$}

\section{Luciano Zoboli ${ }^{3}$}

\section{Jaime Tadeu Oliva 4}

RESUMO - No campo de uma cartografia digital geo-histórica o artigo apresenta mapas inéditos sobre a mobilidade urbana da cidade de São Paulo, produzidos no âmbito de pesquisa coletiva, relativos ao período entre I877 e I930. Em termos de metodologias, o destaque é para a aplicação do georreferenciamento relativo de mapas históricos passando pela vetorização de alguns elementos escolhidos, para, a seguir, trabalhar com uma cartografia analítica transformacional. Esses mapas em sua diversidade de métodos de representação podem permitir novos olhares sobre a mobilidade da cidade de São Paulo e seus reflexos no quadro interacional da cidade. Algo que se procurou fazer no artigo mobilizando também algumas referências teóricas para avaliar esse elemento-chave (o quadro interacional) para a constituição da cidade e de sua sociedade urbana. P PALAVRAS-CHAVE • Geo-história; cartografia digital; georreferenciamento relativo; ur- banidade; mobilidade urbana - ABSTRACT · In a geohistorical digital cartography field, this paper introduces unpublished charts about urban travel in São Paulo city, once produced as part of collective research, related to the period after 1877 until I930. In terms of methodology, it stands out the relative georeferencing of historical maps enforcement and vectorization of a few selected elements as well, to deal, subsequently, with an analytical and transformational cartography. Those charts, in its diversity of representation methods, may enable new perspectives about urban travel in São Paulo city and its repercussions in city interactional framework. This article also sought to bring some theoretical references for assessing this key component - the city international framework - in favour of the town establishment and its urban society. • KEYWORDS - Geo-historical; digital cartography; georeferencing relative; urbanity; urban mobility

Recebido em Io de julho de 2016

Aprovado em 26 de julho de 2016

FONSECA, Fernanda Padovesi; DUTENKEFER, Eduardo; ZOBOLI, Luciano; OLIVA, Jaime Tadeu. Cartografia digital geo-histórica: uma avaliação da mobilidade urbana de São Paulo no final do século XIX e início do século XX. Revista do Instituto de Estudos Brasileiros, Brasil, n. 64, p. I3I-I66, ago. 2016.

DOI: http://dx.doi.org/Io.II6o6/issn.23I6-90IX.voi64pI3I-I66

I Universidade de São Paulo (USP, São Paulo, SP, Brasil).

2 Universidade de São Paulo (USP, São Paulo, SP, Brasil).

3 Universidade de São Paulo (USP, São Paulo, SP, Brasil).

4 Universidade de São Paulo (USP, São Paulo, SP, Brasil). 


\section{INTRODUÇÃo}

Avaliar uma realidade urbana usando uma base empírica constituída por mapas históricos com o acréscimo de uma cartografia digital geo-histórica é um bom ponto de partida para estudar a dinâmica de uma cidade, mas não basta. É bom alertar, pois a euforia com os recursos tecnológicos pode superdimensioná-los, dando-lhes asas de teoria. É óbvio que os novos recursos tecnológicos no campo da cartografia digital são preciosos para uma pesquisa. Todavia, os resultados de uma interpretação pouco valeriam sem a operação de "ferramentas" teóricas. Por isso, ao se estudar uma cidade, a concepção que contextualiza teoricamente o objeto deve ser enunciada primeiramente para que as avaliações sejam bem controladas.

Cidades são realidades que, embora tenham na sua dimensão espacial um dos seus elementos fundantes, não são comumente conceituadas desse ponto de vista. Cidade se define pela gestão da distância geográfica ${ }^{5}$ dos componentes da vida social. Sua realidade caracteriza-se pela presença de elementos materiais e imateriais numa proximidade que tende a zero, sendo, portanto, um fenômeno de concentração de populações, de atividades, de edificações etc. Trata-se de um lugar que pode maximizar e diversificar as interações sociais ${ }^{6}$.

Os atos de relacionar-se e coexistir são as condições universais e fundamento do ser social. Intensificar essas relações com um grau elevado de diversidade é algo que a ocorrência das cidades favoreceu e tornou exponencial [...]. A coexistência permite à

5 Distância geográfica é muito mais que distância em metros, trata-se de uma realidade de grande complexidade.

6 LÉVY, Jacques. Le tournant géographique - penser l'espace pour lire le monde. Paris: Belin, I999. 400 p. (Mappemonde 8).Ver também: LÉVY, Jacques. Ville. In: LÉVY, Jacques; LUSSAULT, Michel (Org.). Dictionnaire de la geographie et de l'espace des sociétés. Paris: Belin, 2003, p. 989. 
cidade ser o lugar do encontro da diferença, o que abre as chances para que se supere, ao menos em parte, as segregações sociais e econômicas, culturais e étnicas?

Historicamente, a despeito da enorme diversidade existente entre as cidades, elas impulsionaram e revolucionaram as artes, as ciências, as filosofias etc. O historiador Fernand Braudel tematiza esse largo espectro histórico de vocação interacional das cidades: "cidades existem desde a Pré-História. São estruturas multisseculares que fazem parte da vida comum. Mas são também multiplicadores, capazes não só de se adaptarem à mudança, como de contribuírem poderosamente para ela”.

Se o testemunho de Braudel afirma a cidade como espaço de transformações, nas cidades contemporâneas isso é inegável. Conforme Olivier Mongin, a cidade é uma "multiplicadora de relações, aceleradora de trocas". A generalização contemporânea das cidades em escalas inimagináveis nos habituou a considerar um "mundo urbano" como elemento central da realidade atual. Fenômenos de importância para a compreensão da atualidade se relacionam com esse mundo urbano: coespacialidade ${ }^{\text {Io }}$ propiciada pela abundância telecomunicacional; questões de mobilidade que alargam (ou não) nossos contextos relacionais; comutadores espaciais, como aeroportos, parques temáticos, shopping centers; segregação social crescente; urbanidade ${ }^{\mathrm{II}}$ como valor alternativo e de resistência às tendências sociais reificantes etc. ${ }^{\text {I2 }}$.

Certamente essa complexidade do mundo urbano resulta de várias transformações evolutivas, de rupturas e de processos criativos de longa gestação. Tal é a importância das realidades urbanas, que reconstituí-las em sua dinâmica é tarefa capital.

\section{GEO-HISTÓRIA: UM OLHAR RETROSPECTIVO}

As elaborações que seguem se inserem nos estudos históricos do mundo urbano, dando essencialidade à questão espacial. Para tal, um recurso teórico de proa disponível é a geo-história ${ }^{\mathrm{I3}}$ aplicada às cidades. $\mathrm{O}$ olhar geo-histórico descreve e

7 OLIVA, Jaime Tadeu. A cidade como ator social: a força da urbanidade. In: ALESSANDRI CARLOS, Ana Fani; LEMOS, Amália Inês Geraiges (Org.). Dilemas urbanos: novas abordagens sobre a cidade. São Paulo: Contexto, 2003, p. 73-80. p. 74 .

8 BRAUDEL, Fernand. A dinâmica do capitalismo. Rio de Janeiro: Rocco, I987, p. 22.

9 MONGIN, Olivier. A condição urbana: a cidade na era da globalização. São Paulo: Estação Liberdade, 2009, p. 29.

Io Espaços conectados, multiescalares, numa mesma relação.

II Urbanidade é a realização do caráter interacional da cidade. Cidades com urbanidade favorecem uma integração maior dos grupos sociais, dispõem os recursos urbanos de modo mais acessível aos membros da sociedade, tornando-se mais produtivas e criativas no conjunto da vida social. Cidades mais compactas, densas e diversas se coadunam mais com a urbanidade.

I2 LUSSAULT, Michel. L'homme spatial: la construction sociale de l'espace humain. Paris: Seuil, 2007.

I3 GRATALOUP, Christian. Géohistorie. In: LÉVY, Jacques; LUSSAULT, Michel (Org.). Dictionnaire de la geographie et de l'espace des sociétés. Paris: Belin, 2003, p. 40I. 
interpreta os períodos históricos de uma cidade tendo como centro a organização espacial produzida. Desse modo, condições espaciais pretéritas são apreendidas como um "estudo geográfico de processos históricos" ${ }^{4}$.

Descrever e interpretar a organização espacial de uma cidade tem nos diversos recursos de representação bons aliados metodológicos. Aqui irá se expor interpretações derivadas de um "saber visual" muito desenvolvido nas cidades, que é o mapa ${ }^{\mathrm{IS}}$. Para isso, mobilizaram-se mapas históricos e produziram-se outros com o objetivo de resgatar a dinâmica dos transportes e como essa última participou na configuração de uma cidade na virada do século XIX para o século XX, no caso São Paulo.

Uma questão com a qual se deparou foi a que os mapas históricos de São Paulo representam repetidamente as estruturas físicas fixas do local e dão "pouca vazão" para os elementos dinâmicos que estão modificando a cidade de forma importante. E justo num momento em que a cidade estava vivendo um crescimento demográfico exponencial, passando de 3I.385 (I872) para 579.033 habitantes (I920) ${ }^{\text {I6 }}$.

$\mathrm{Na}$ verdade, havia (e há) uma naturalização da representação dos elementos fixos da paisagem num espaço cartográfico, visto como espaço absoluto. Porém, a cartografia não deve ficar limitada à essa base. Uma tomada de posição é a de não identificar o espaço absoluto ao espaço geográfico. A ideia é que a apreensão social de espaço não se separa das formas sociais que se adotam para medi-lo. Por isso, um dos componentes elementares do espaço é a métrica ${ }^{\mathrm{I}}$. No caso da cartografia com base no espaço absoluto, a métrica é a euclidiana. Outras métricas pressupõem uma abertura para a concepção de espaço relativo, fronteira para a cartografia explorar ${ }^{18}$.

Mesmo com fundo absoluto, mapas podem ser mais socializados. Isso é necessário para a revelação das dinâmicas sociais que têm maior poder heurístico para a interpretação das cidades. Mas, se acrescermos a esse repertório mapas com outras métricas, o potencial heurístico aumentará de forma importante. A geo-história pode, então, lançar mão de algumas possibilidades novas em seus estudos retrospectivos. Trata-se de recursos digitais aplicados à cartografia. Um exemplo precursor foi realizado pelo historiador Bernard Lepetit em parceria com os geógrafos Colette Cauvin e Henry Reymond. Num trabalho de I987, novas metodologias estatísticas

\footnotetext{
I4 Ibidem.

I5 HARLEY, John Brian. A nova história da cartografia. O Correio da Unesco (mapas e cartógrafos), Brasil, ano I9, n. 8, ago. I99I, p. 4-9. p. 5.

I6 PREFEITURA DE SÃO PAULO. Histórico demográfico do município de São Paulo. - Tabelas. Disponível em: 〈http://smdu.prefeitura.sp.gov.br/historico_demografico/tabelas.php〉. Acesso em: 20 jun. $20 I 6$.

I7 LÉVY, Jacques. Métrique. In: LÉVY, Jacques; LUSSAULT, Michel (Org.). Dictionnaire de la géographie et de l'espace des sociétés. Paris: Belin, 2003, p. 607-609. Outros elementos são: a substância, que define o tipo de distância que corresponde a um dado fenômeno, e a escala, que define os limites de descontinuidade na medida das distâncias. I8 FONSECA, Fernanda Padovesi. A inflexibilidade do espaço cartográfico, uma questão para a geografia: análise das discussões sobre o papel da cartografia. Tese (Doutorado em Geografia). Faculdade de Filosofia, Letras e Ciências Humanas - FFLCH da Universidade de São Paulo - USP, 2004, p. 40.
} 
e cartográficas processadas em computador reconstruíram a organização do espaço funcional postal francês de meados do século XVIII ${ }^{\text {I9 }}$.

Isso considerado, o objetivo do artigo foi buscar algo da dinâmica da cidade e exercitar novas formas de representação, onde o mapa trabalha também com fundos de métricas não euclidianas. Escolheu-se representar o sistema de meios de transportes da cidade no período estudado. Para tanto, mobilizaram-se as metodologias da cartografia digital.

\section{Cartografia digital (OU COMPUTACiOnal}

A expressão cartografia digital aglutina elementos relacionados às práticas cartográficas que utilizam a computação. Em francês há um termo que é mais abrangente, mas que engloba essa cartografia: géomatique ${ }^{20}$. Para Guermond ${ }^{21}$, a geomática designa a análise de dados espaciais, onde o computador desempenha papel-chave nos procedimentos de pesquisas. $\mathrm{O}$ autor alerta que esse termo engloba o Sistema de Informações Geográficas (SIG), a utilização do GPS (Global Positioning System) e softwares diversos.

Nos anos I960 a revolução quantitativa na geografia foi terreno fértil para a experimentação de técnicas computacionais na análise espacial. O geógrafo Waldo Tobler ${ }^{22}$ relata que nessa época, na Universidade de Washington, ele já usava métodos quantitativos, com apoio de computadores. Na Universidade de Michigan (I96I) deparou-se com uma cartografia manual. Formulou então um curso de cartografia:

[...] o meu curso foi uma tentativa de formalizar a noção de que métodos cartográficos eram usados com frequência por geógrafos em suas análises e investigações. Daí o nome "Cartografia Analítica", muito embora o curso começasse como "Cartografia Computacional”"23.

Daí em diante, esse desenvolvimento se acelerou, e os cartógrafos passaram a empregar, em seus trabalhos, o computador. Colette Cauvin denomina essas práticas como cartografia analítica transformacional ${ }^{24}$. Essa cartografia foi iniciada por Tobler em I96I e desenvolvida por K. Clarke em I990, nos EUA e na França, por

I9 CAUVIN, Colette; LEPETIT, Bernard; REYMOND, Henry. Cartes postales: un espace de relation dans la France pré-industrielle. Histoire ermesure, v. 2, n. 3-4, I987, p. 89-II3. Disponível em: 〈http://www.persee.fr/web/revues/ home/prescript/article/hism_0982-I783_I987_num_2_3_I327>. Acesso em: 20 jun. 2016.

20 Em português, geomática; em inglês, geomatics.

2I GUERMOND, Yves. Géomatique. In: LÉVY, Jacques; LUSSAULT, Michel (Org.). Dictionnaire de la geographie et de l'espace des sociétés. Paris: Belin, 2003, p. 402.

22 TOBLER, Waldo. The development of analytical cartography: a personal note. Disponível em: <http://www. geog.ucsb.edu/ kclarke/Geographyı28/Tobler20oo.pdf $>$. Acesso em: 20 jun. 2016.

23 Ibidem, p. I (tradução nossa).

24 CAUVIN, Colette; ESCOBAR, F.; SERRADJ, A. Cartographie thematique I. Paris: Lavoisier, 2007. 
Sylvie Rimbert e pela própria Colette Cauvin. As possibilidades técnicas são várias: processar pacotes volumosos de dados, gerar diversas visualizações das relações entre os objetos e os dados espacializados, aplicando métodos de produção impossíveis de serem realizados manualmente. Pode-se, testar diversas transformações ${ }^{25}$ que vão operar como suportes para as análises geográficas, daí a designação cartografia analítica transformacional.

Assim, com os recursos teóricos de apreensão das cidades e da geo-história somados àqueles da cartografia digital, empreendeu-se um estudo sobre a cidade de São Paulo entre I877 e I930, dando relevo à questão da mobilidade urbana.

\section{Metodologia na avaliação da mobilidade de São Paulo}

No que diz respeito à mobilidade urbana foram tratados em particular as redes de bondes por tração animal, de bondes elétricos, assim como o que havia de rede ferroviária, o que inclui as linhas dos chamados tramways ${ }^{26}$. Seguem os procedimentos.

\section{Seleção dos mapas históricos}

Para este fazer geo-histórico mobilizou-se um mapeamento do município de São Paulo de I930, feito no âmbito de projeto executado pela empresa italiana Sara ${ }^{27}$. Trata-se de um mosaico de cartas que foi trabalhado com SIG, utilizando especificamente o software ArcGis 9.3 ${ }^{28}$. O mosaico do Sara ${ }^{29}$ tem 58 cartas na escala de I:I.00o (figura I) e 67 cartas na escala de I:5.000 (figura 2). Os dois mosaicos estão em formato matricial e referenciados em sistema geodésico atual e Datum SAD69, fuso $23 \mathrm{~S}^{30}$.

\footnotetext{
25 Por exemplo: transformação dos localizantes; generalização e mudança da projeção cartográfica; transformação cartográfica de posição (anamorfose); transformação semiótica com base na semiologia gráfica etc. Ver: DUTENKEFER, Eduardo. Representações do espaço geográfico: mapas dasimétricos, anamorfoses e modelização gráfica. Dissertação (Mestrado em Geografia). Faculdade de Filosofia, Letras e Ciências Humanas - FFLCH da Universidade de São Paulo - USP, 2010.

26 O que é denominado bonde nas cidades brasileiras corresponde ao tramway em inglês. No entanto, as linhas de tramways existentes no período (Cantareira e Santo Amaro) eram linhas de trem, com locomotiva e vagões.

27 Società Anonima Rilevamenti Aerofotogrammetrici.

28 Da empresa Environmental Systems Research Institute (Esri).

29 Mosaico cedido ao Departamento de Geografia da FFLCH, disponível no Laboratório de Cartografia e Geoprocessamento André Libault, pela Procuradoria do Patrimônio Imobiliário, órgão da Procuradoria Geral do Estado de São Paulo.

30 Eles foram georreferenciados pela Sulsoft (www.sulsoft.com.br), que desenvolveu uma rotina em IDL (Interactive Data Language). Disponível em: 〈http://www.sulsoft.com.br/idl/index.php?link=index >. Acesso em: 2I nov. 20I3.
} 


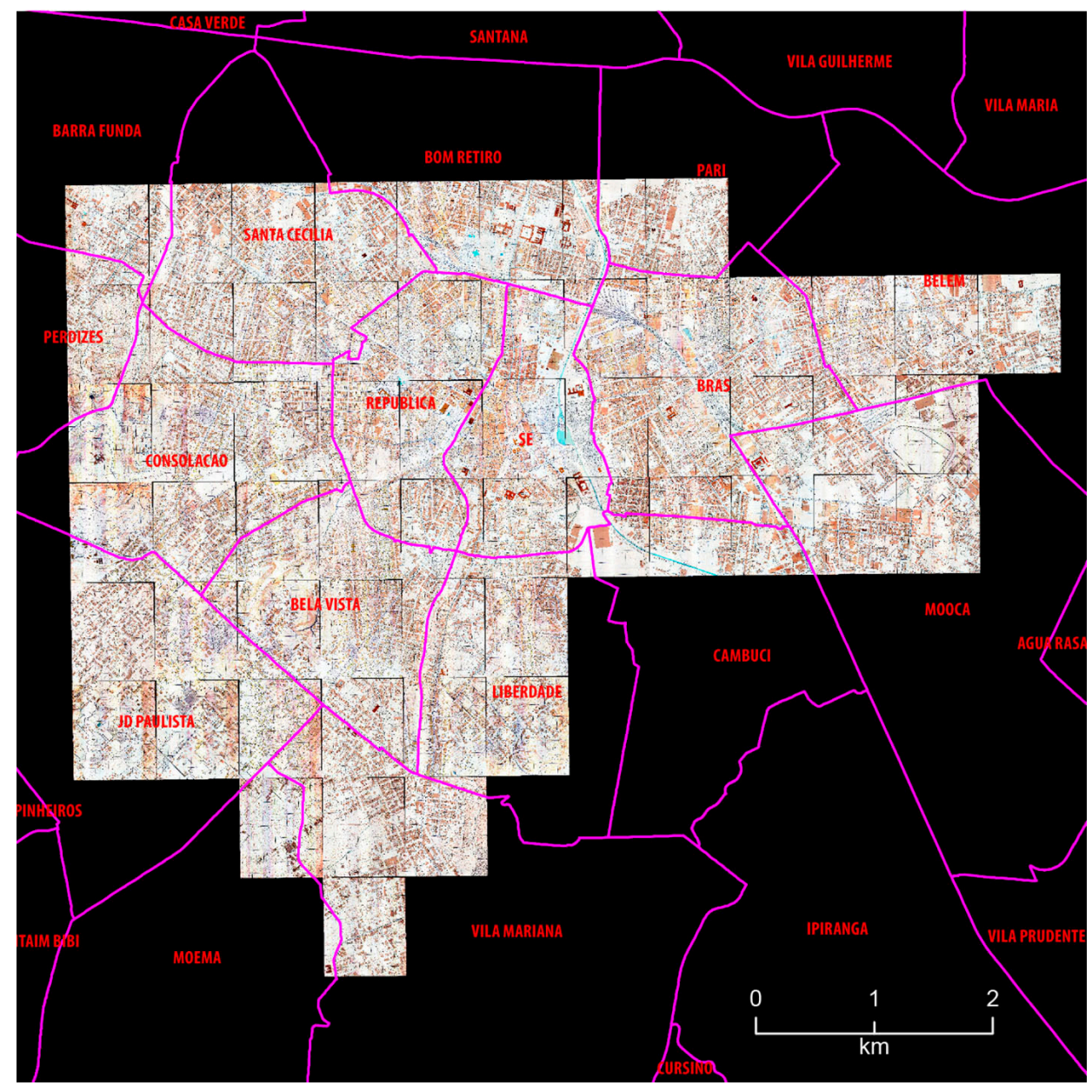

Figura I - Mosaico do Sara I930 com as 58 cartas de escala I:I.00o. Representa também os limites dos atuais distritos do município de São Paulo 


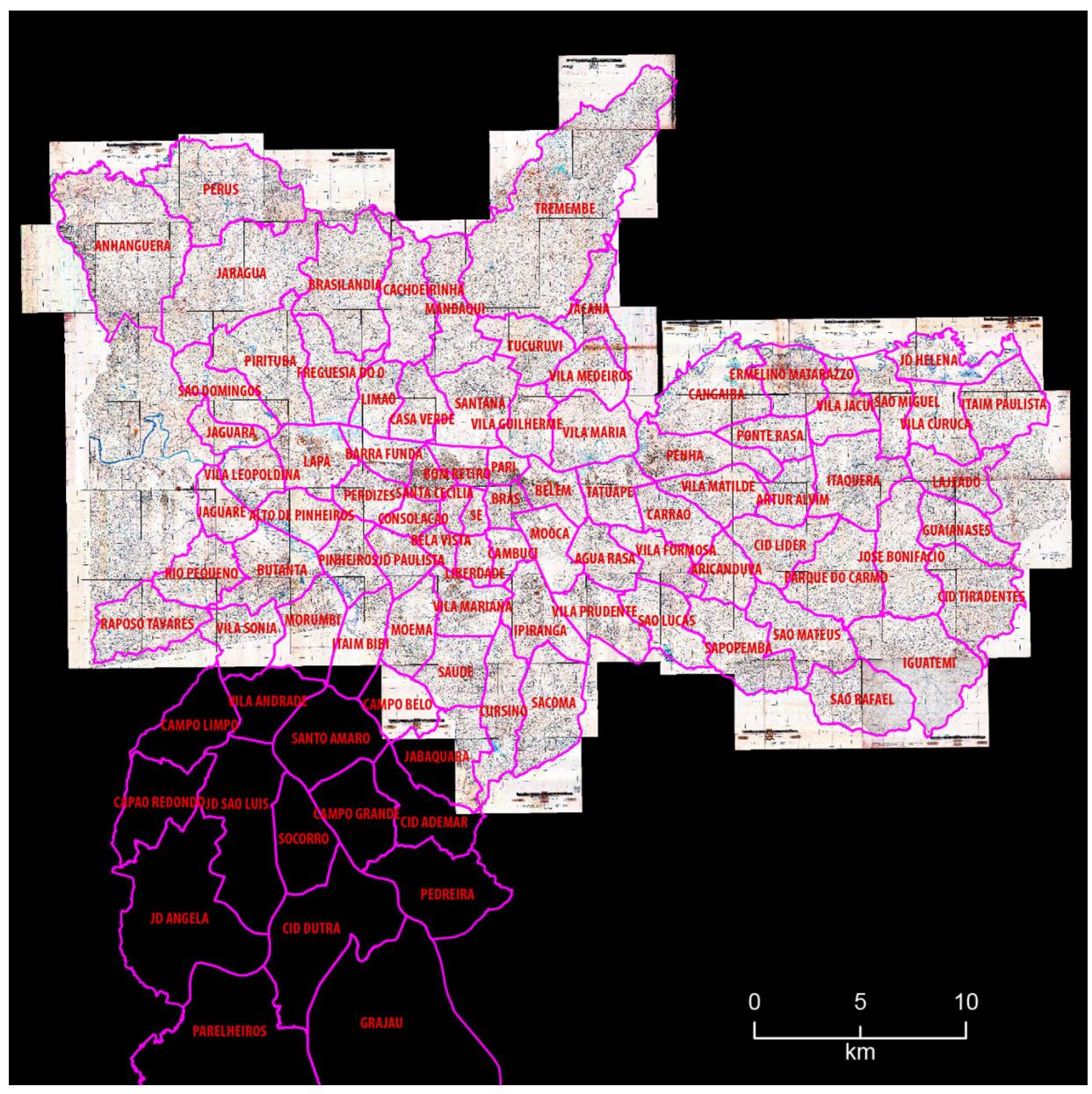

Figura 2 - Mosaico do Sara I930 com as 67 cartas de escala I:5.000. Representa também os limites dos atuais distritos do município de São Paulo

Além do Sara foram utilizados no estudo mapas anteriores a I930, já digitalizados e com boa resolução:

I) Mappa da capital da P. ${ }^{\text {cia }}$ de S. Paulo, de Fernando Albuquerque e Jules Martin (I877) ${ }^{31}$;

2) Planta da cidade de São Paulo, de Henry B. Joyner (Cia. Cantareira de Águas e Esgotos) $(1881)^{32}$;

3I INFORMATIVO AHM. Arquivo Histórico Municipal Washington Luís. São Paulo antigo: plantas da cidade, n. 20, set.-out. 2008. Disponível em: 〈http://www.arquiamigos.org.br/info/info20/i-I877.htm〉. Acesso em: 20 jun. 2016.

32 Ibidem. Disponível em: 〈http://www.arquiamigos.org.br/info/info2o/i-I88I.htm〉. Acesso em: 20 jun. 2016. 
3) Planta da capital do estado de S. Paulo e seus arrabaldes, de Jules Martin (1890)33;

4) Planta geral da capital de São Paulo, de Gomes Cardim (I897)34;

5) Planta geral da cidade de São Paulo, de Alexandre Mariano Cococi e Luís Fructoso e Costa (I905)35;

6) Planta geral da cidade de São Paulo, da Commissão Geographica e Geologica (I9I4) ${ }^{36}$.

Essas representações viabilizam um olhar sequencial sobre a dinâmica da cidade, sobretudo no que diz respeito à configuração territorial paulistana, mas também vai possibilitar o olhar sequencial sobre a infraestrutura de transportes. Buscou-se "introduzir" nos mapas um aporte tecnológico com o intuito de criar um banco de dados integrado para as comparações dos mapas históricos da cidade no SIG.

\section{O georreferenciamento relativo dos mapas de São Paulo}

Para o georreferenciamento dos mapas históricos utilizou-se a metodologia proposta por Eduardo Dutenkefer ${ }^{37}$, que busca apreender os mesmos objetos espaciais com as mesmas relações visuais de distância existentes nos mapas originais. Trata-se do denominado georreferenciamento relativo. Esse nome faz alusão à concepção de espaço geográfico como espaço relativo ${ }^{38}$. Essa metodologia difere daquela que é orientada principalmente pela busca da precisão cartográfica e que tem como base a lógica geométrica do espaço absoluto. Nesse último caso, o georreferenciamento é uma forma de corrigir os "erros" de localização dos mapas históricos, tudo segundo uma verdade topográfica atual. Caso o mapa antigo seja colocado nessa grade corrigida, os elementos representados deixarão de ter a mesma relação de distância.

33 Ibidem. Disponível em: <http://www.arquiamigos.org.br/info/info2o/i-I89o.htm>. Acesso em: 20 jun. $20 I 6$.

34 Ibidem. Disponível em: 〈http://www.arquiamigos.org.br/info/info2o/i-I897.htm>. Acesso em: 20 jun. $20 I 6$.

35 PREFEITURA DE SÃO PAULO. Histórico demográfico do município de São Paulo. Disponível em: <http:// smdu.prefeitura.sp.gov.br/historico_demografico/img/mapas/I905.jpg>.

36 COMMISSÃO GEOGRAPHICA E GEOLOGICA. Planta geral da cidade de São Paulo. Memória urbana: a Grande São Paulo até I940. São Paulo: Arquivo do Estado, Emplasa, Imprensa Oficial, 200I, v. 3. 76 x 62,64 cm. Escala: I:20.000.

37 Ver: DUTENKEFER, Eduardo. Metodologia para um saber e um fazer geo-histórico: análise de espacialidades pretéritas utilizando instrumentos computacionais, $20 \mathrm{I}_{4}$ (mimeo.)

$38 \mathrm{Na}$ tradição filosófica as concepções de espaço podem ser resumidas por uma oposição entre absoluto/ relativo. Espaço absoluto diz respeito à existência de um postulado (o de absoluto) no qual se afirma a existência do espaço independentemente das realidades que nele se desdobram. Se o espaço é, ao contrário, relativo, ele depende na sua própria realidade dos objetos que ali se encontram. A metáfora conteúdo/continente perde sua pertinência. Para Leibniz, os objetos espacializados entram, por meio de suas relações, na construção do espaço. A concepção de espaço relativo é a base essencial para a formulação teórica do espaço social, e para a renovação da geografia. Só desse ponto de vista pode-se falar em produção do espaço pela sociedade, ou pode-se afirmar o espaço como um ingrediente interno da dinâmica social. Ver: LÉVY, Jacques; LUSSAULT, M. Espace. In: LÉVY, Jacques; LUSSAULT, Michel (Org.). Dictionnaire de la geographie et de l'espace des societes. Paris: Belin, 2003, p. 325-333. 
No georreferenciamento relativo, ao contrário, será mantida a integridade do mapa. O que era mais perto ou mais longe num mapa histórico não reflete necessariamente um erro de precisão ${ }^{39}$, já que outras razões podem estar operando. Não é improvável que alguns objetos tenham sido colocados mais próximos entre si (sem referência à distância euclidiana) em razão de um maior número de relações, ou mesmo de um desejo de mostrar um dado elemento mais integrado à cidade. Algo assim seria um meio de mostrar de forma mais fiel a lógica geográfica das cidades ${ }^{40}$.

Por isso, no georreferenciamento relativo o empenho é manter as relações originais do mapa antigo. Mesmo mantendo o respeito ao mapa original é possível e útil a realização do georreferenciamento. Com esse instrumento tecnológico vai se gerar uma grade espacial euclidiana que permitirá diversas outras operações, assim como o controle do posicionamento original em relação a essa grade (os deslocamentos).

$\mathrm{O}$ georreferenciamento relativo foi executado com o software MapAnalyst ${ }^{4 \mathrm{I}}$. As ferramentas do MapAnalyst fornecem dados de escala, ângulo de rotação e alguns indicadores estatísticos que permitem um exercício de comparação de mapas de diferentes períodos de um dado lugar $4^{42}$. No caso, o trabalho foi direcionado para estabelecer a comparação dos mapas por meio de pontos de controle (Linked Points). Os procedimentos foram os que seguem:

I) A comparação inicia-se no MapAnalyst cotejando o mapa sem referenciais geodésicos com um mapa georreferenciado. Para determinar os Linked Points dos mapas históricos de São Paulo (Old Maps), o cotejo de referência foi com os mosaicos Sara (New Reference Maps). As cartas na escala I:I.000 referenciaram os mapas de I877, I88I e I890, e as cartas na escala I:5.000 os mapas de I897, I905 e I9I4.

39 A própria ideia de erro é relativa, pois a busca da precisão pelos elaboradores originais estava condicionada pelo contexto das técnicas e das formas de medir da época.

40 Um célebre caso de uso deliberado de distâncias alteradas em relação ao fundo euclidiano é o mapa do metrô de Londres (paradigma de mapas de metrôs do mundo). Antes, o mapa do metrô de Londres exprimia as distâncias absolutas e com isso dava a impressão de áreas da cidade desintegradas do conjunto, o que de fato não era real visto que o metrô realizava a integração. O mapa moderno do metrô de Harry Beck altera essa lógica dando ênfase às conexões, uniformizando as distâncias entre as estações. Com isso as distâncias são medidas conforme o número de estações e as conexões da rede, o que é de fato um modo muito mais real de medir distâncias numa estrutura reticular. Ver: ELLIMAN, Paul. Signal Failure. In: ABRAMS, Janet; HALL, Peter (Ed.). Else/where: mapping new cartographies of networks and territories. Minneapolis: University of Minnesota Press, MN, 2006, p. I66-I75.

4I MapAnalyst. The map historian's tool for the analysis of old maps. Disponível em: 〈http://mapanalyst.org 〉. Acesso em: 8 jan. 2012.

42 JENNY, Bernhard; WEBER, Adrian; HUERNI, Lorenz. Visualizing the planimetric accuracy of historical maps with MapAnalyst. Cartographica: The International Journal for Geographic Information and Geovisualization, v. 42, issue I, 2007, p. 89-94. 
2) Estabeleceram-se os pontos de controle ${ }^{43}$ pela comparação de quadras, ruas e cruzamentos presentes tanto no Old Map quanto no New Reference Map. A distribuição dos pontos procurou abranger várias áreas dos mapas para ter um número grande de pontos homólogos por toda a representação. A figura 3 mostra uma tela do aplicativo MapAnalyst com um mapa histórico (Old Map) e o Sara (New Reference Map).

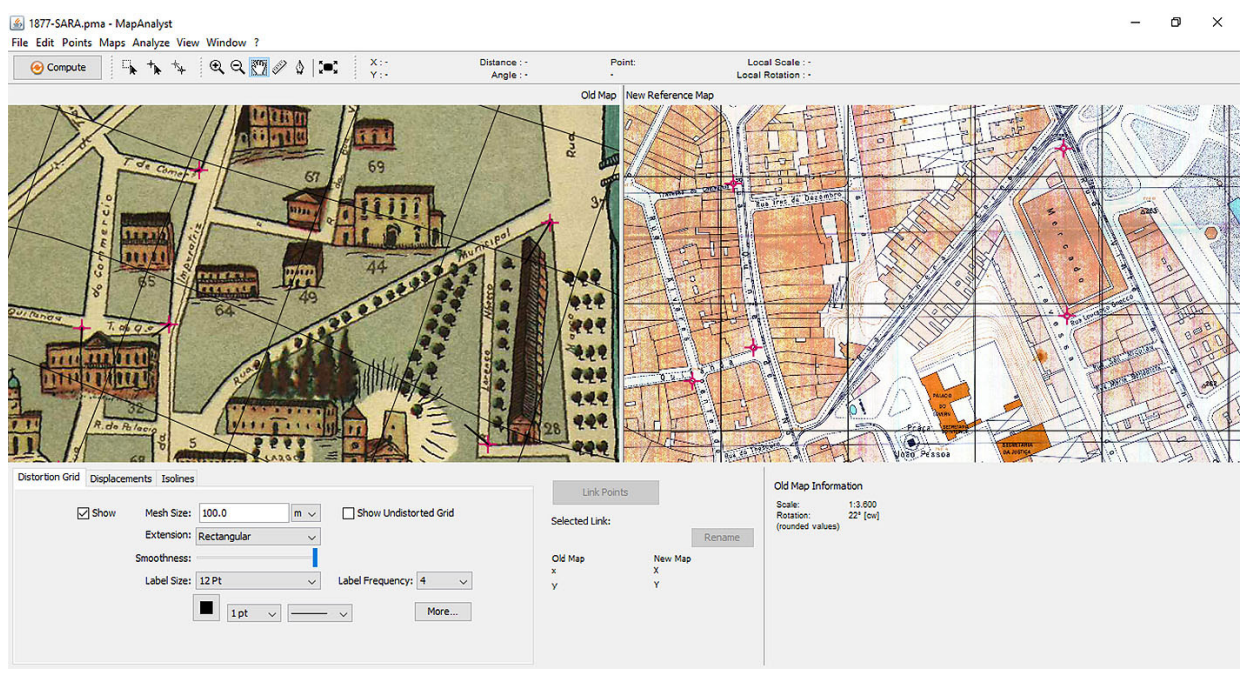

Figura 3 - À esquerda, o mapa histórico de I877; à direita, o Sara I930 (ambas as telas são referentes às mesmas áreas)

3) Os mapas históricos, ao serem georreferenciados no ArcGis 9.3, explicitaram seus indicadores de distorção (Distortion Drid) e os vetores de deslocamento entre os pontos homólogos (pontos de controle na base do New Reference Map) exportados no formato shapefile (shp).

4) No ArcGis 9.3 a grade de distorção e os vetores de deslocamento do Sara vão ser as referências para o georreferenciamento dos mapas históricos anteriores ao Sara. No caso, a "ponta do vetor de deslocamento" é o ponto homólogo no mapa histórico. Esses "pontos" são usados como pontos de controle para georreferenciar, de modo relativo, o mapa antigo. Esse procedimento, apesar de não ser usual, de certo modo não sendo previsto na análise dos mapas antigos no MapAnalyst, mostrou-se pertinente como meio para não perder as características originais do mapa histórico.

5) Após o georreferenciamento relativo conseguiu-se relacionar diferentes mapas

43 Foram utilizados: 90 pontos de controle para a representação de I877; 94 para a deI 88I; 52 para a de I890; 93 para a de I897; I24 para a de I905; e I33 pontos para a de I9I4. A quantidade de pontos foi determinada de acordo com a escala da representação e com as possibilidades de comparação entre o Old Map e o New Reference Map. 
para o trabalho de vetorização 44 e também se construiu um banco de dados de cada representação.

6) Com os mapas georreferenciados, selecionaram-se os elementos para a investigação da rede de transportes. Para uma boa sistematização do que seria vetorizado, utilizou-se como estratégia a separação por grupos de análise. Assim, o primeiro grupo foi constituído pelos mapas de I877, I88I e I890; o segundo grupo incluiu os de I897, I905 e I9I4. Por último, alguns elementos da base cartográfica do Sara também foram vetorizados, o que na verdade se constituiu no terceiro grupo ${ }^{45}$.

7) Em relação ao primeiro grupo tratou-se temas referentes ao perímetro de representação da cidade e aos transportes. No primeiro item, houve um esforço em duas frentes: a primeira diz respeito à interpretação sobre a cidade daqueles mapas, na qual se estabeleceu uma diferenciação entre a forma mais consolidada da cidade e as áreas em consolidação, assinalando também os vetores de expansão da cidade; já na segunda frente se utilizou uma vetorização sobre elementos presentes naquelas representações, onde se mobilizou a figura dos rios (e das várzeas) enquanto elementos naturais predominantes na paisagem e no cotidiano daquela São Paulo. No segundo item, a preocupação foi reforçar a representação dos transportes da época, representando os bondes movidos por tração animal (no mapa de I877), as ferrovias e suas estações (presentes nos mapas de I877, I88I e I890).

8) Já no segundo grupo destaca-se um recorte mais amplo dos mapas, trabalhando com áreas para além da área central da cidade. Priorizou-se a questão da rede de transporte da época: no primeiro mapa do lote (I897) vetorizou-se a rede de linhas de bondes por tração animal da Companhia Viação Paulista reconstruindo os percursos a partir de fonte bibliográfica ${ }^{46}$; no segundo e terceiro mapas (I905 e I9I4) as linhas de bondes elétricos da Light foram vetorizadas também com fonte bibliográfica ${ }^{47}$. Em todos os mapas também foram vetorizadas as ferrovias e os tramways, informações presentes nos mapas históricos.

9) Em relação ao Sara (terceiro grupo) foram vetorizadas as redes de bonde, ferrovias e estações. Todas essas informações se encontravam nesse mapeamento, que é bastante completo. Posteriormente, todas essas informações vetorizadas foram confrontadas com fontes bibliográficas.

44 Vetorizar é transformar arquivos digitalizados em formato raster (matricial) em arquivos vetoriais matemáticos do tipo ponto, linha e polígono.

45 A tese de doutorado de Iara Sakitani Kako (O papel dos trilhos na estruturação territorial da cidade de São Paulo de I867 a I930. Tese (Doutorado em Geografia Humana). Faculdade de Filosofia, Letras e Ciências Humanas - FFLC da Universidade de São Paulo - USP, 20I3) foi referência na escolha de alguns elementos a serem vetorizados. Mas diferenças de metodologia e de interpretação dos mapas suscitaram a escolha de outros elementos e um processo de vetorização feito para além das informações presentes nas plantas, utilizando-se para tal de fonte bibliográfica.

46 PINTO, Alfredo Moreira. A cidade de São Paulo em I900. São Paulo: Governo do Estado, I979.

47 STIEL, Waldemar Correa. História dos transportes coletivos em São Paulo. São Paulo: McGraw-Hill do Brasil, I978. 
Io) Por fim, chegou-se à geração de uma cartografia digital geo-histórica com acabamento com softwares tipo Inkscape ${ }^{48}$.

Os resultados desse georreferenciamento relativo serão analisados no próximo segmento.

\section{AVAliação dos MAPAS digitais GEO-HISTÓRICOS}

A avaliação da rede de bondes no período entre I877 e I930 revela quais foram as mudanças decisivas, não somente para uma avaliação da mobilidade da cidade, mas para entender a conformação da cidade incluindo as novas áreas de produção do espaço urbano. Quer dizer: pode-se partir desse aspecto para uma interpretação geral da cidade, visto a importância da mobilidade no quadro interacional das realidades urbanas.

Os primeiros mapas feitos sobre os transportes tiveram como referência construtiva a coleção de mapas históricos de São Paulo do primeiro grupo (I877, I88I e I890) e também a tese de Iara Sakitani Kako49. A cidade nesse período vivia uma grande mudança. Esse período foi designado como a "segunda fundação de São Paulo"so graças a uma série de condições políticas, econômicas e sociais que culminaram num grande crescimento populacional. As áreas que os mapas representavam correspondiam a um espaço urbano restrito referente à ocupação colonial, praticamente toda concentrada na "colina histórica" (e no "triângulo histórico") $)^{5}$.

Os novos mapas foram construídos a partir de elementos selecionados e reinterpretados dos mapas antigos, ou introduzidos de outras fontes, que em seguida foram vetorizados e aplicados formando uma nova "camada" sobre o mapa antigo. Esses novos mapas estão elencados nas figuras 4, 5 e 6.

\footnotetext{
48 Software para edição de gráficos vetoriais de código aberto disponível em: 〈https://inkscape.org/pt/>

49 KAKO, Iara Sakitani, op. cit.

50 PAULA, E. S. de. A segunda fundação de São Paulo. Da pequena cidade à grande metrópole de hoje. Revista de História - USP n. I7, I954, p. I67-I79.

5I O marco de fundação da cidade de São Paulo e o espaço urbano que se estrutura a seguir se dispõem numa colina que se ergue entre os vales do rio Tamanduateí e o do córrego Anhangabaú. Nessa "colina histórica", instalaram-se conventos das ordens religiosas dos carmelitas, dos beneditinos e dos franciscanos em suas bordas, e esses polos foram vistos como vértices de um triângulo urbano que se estruturou na colina: o "triângulo histórico".
} 


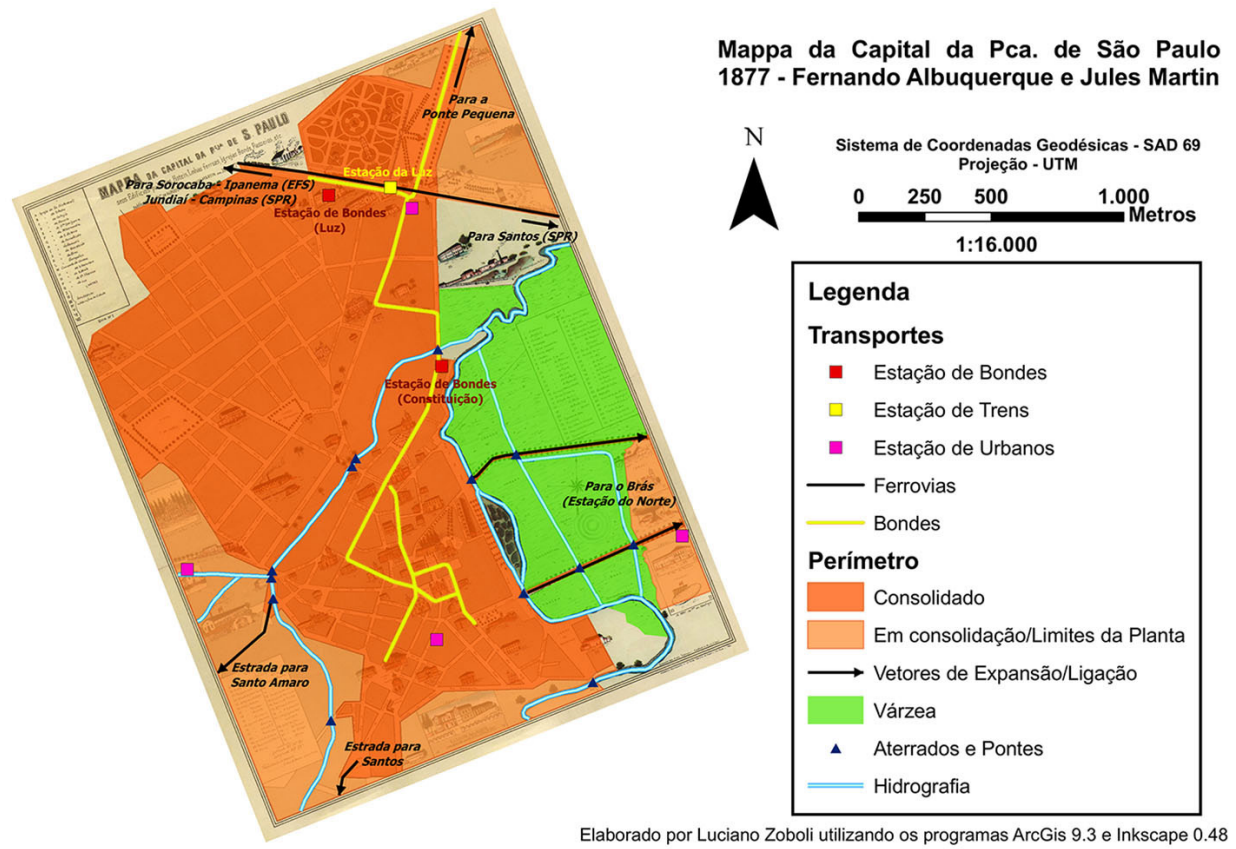

Figura 4-São Paulo, em I877

O mapa que serviu de referência para o novo mapa da figura 4 foi publicado em I877 e elaborado como um mapa turístico, conforme afirma Nestor Goulart Reis Filho ${ }^{52}$. Eudes Campos ${ }^{3}$ detalha que a intenção de Fernando Albuquerque e de Jules Martin ao fazer o mapa era a de orientar pessoas do interior e estrangeiros que vinham tratar de negócios e trabalhar em São Paulo.

Pioneiramente, ele traz a representação das linhas de bondes de tração animal, assim como linhas de trens e várias estações 54 . Desde 1872 a cidade já possuía uma malha de trilhos de bondes movidos a tração animal. No caso de São Paulo, como assinala Roberto P. Toledo, eram burros, "os carros eram puxados por parelhas que, nos percursos mais longos, eram trocadas” 55 .

As linhas de bondes percorriam quase toda a cidade da época. Segundo Richard Morse, "Em I877 havia sete linhas de 25 quilômetros de trilhos, 3I9 animais e 43

52 REIS FILHO, Nestor Goulart. São Paulo: vila cidade metrópole. Prefeitura de São Paulo, 2004.

53 Eudes Campos apud GOUVÊA, José P. Neves. A produção do espaço de São Paulo através de suas representações cartográficas. Dissertação (Mestrado em Tecnologia da Arquitetura). Faculdade de Arquitetura e Urbanismo FAU da Universidade de São Paulo - USP, 20Io, p. 99.

54 Ibidem.

55 TOLEDO, Roberto P. A capital da vertigem (uma história de São Paulo de I900 a I954). Rio de Janeiro: Objetiva, 20I5, p. 3I-32. 
carros que transportavam I.500.000 passageiros por ano. Além dessas linhas, havia uma pequena estrada de ferro que ligava Santo Amaro, na periferia, à cidade”56.

O número de passageiros/ano é de impressionar, o que demonstra o uso intenso que a população (por volta de 35 mil habitantes) 57 fazia não só dos transportes, mas da cidade.

O novo mapa construído sobre o de I877 destaca as estações das linhas de bonde e de trem, já presentes na representação original. Assim como realça e distingue a área urbana consolidada e as áreas em consolidação. Também aponta as direções dos vetores de expansão da cidade, algo possível entre outras razões por conta do acesso de mapas posteriores que mostram a efetiva expansão. A comparação de diferentes mapas históricos permite que as vetorizações sejam feitas para verificar por onde a cidade cresceu, quais os caminhos que foram mais decisivos e o que os mapas projetaram e o que realmente aconteceu.

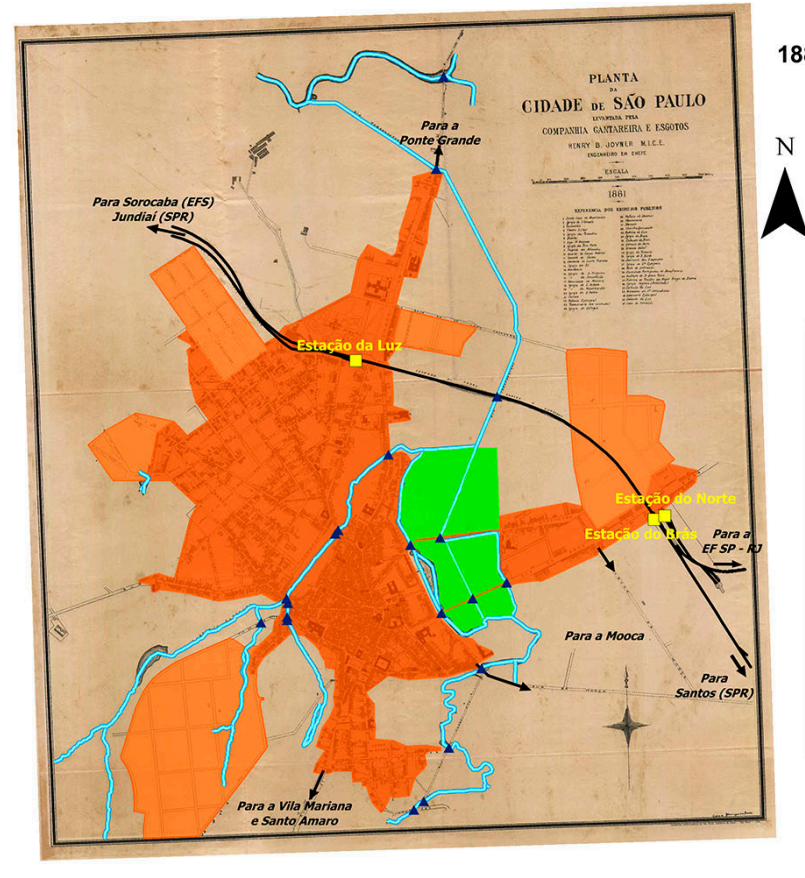

Planta da Cidade de São Paulo 1881 - Henry P. Joyner (Cia. Cantareira de Águas e Esgotos)

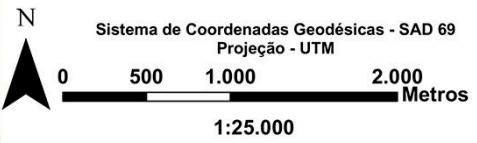

\section{Legenda \\ Transportes}

$\square \quad$ Estação de Trens

— Ferrovias

Perímetro

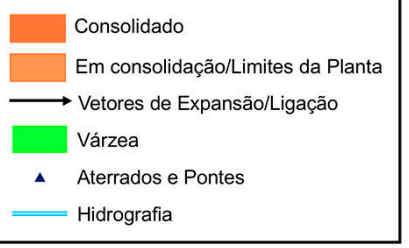

Elaborado por Luciano Zoboli utilizando os programas ArcGis 9.3 e Inkscape 0.48

Figura 5-São Paulo em I88I

Por sua vez o mapa de referência para o novo mapa da figura 5 foi produzido em I88I pela Cia. Cantareira de Águas e Esgotos, e sua finalidade está vinculada às necessidades de controle e planejamento das atividades da empresa. Trata-se de um

56 MORSE, Richard M. Formação histórica de São Paulo (de comunidade a metrópole). São Paulo: Difel, I970, p. 248. 57 A população recenseada em I872 era de 3I.385 habitantes. 
mapa cadastral. Conforme Nestor Goulart Reis Filho ${ }^{58}$ essa é a segunda planta cadastral de São Paulo ${ }^{59}$.

No novo mapa destaca-se novamente a distinção entre a área de urbanização consolidada e a área em consolidação, assim como a indicação dos vetores de expansão da cidade. Esses vetores foram depreendidos tendo em vista o mapa anterior e também mapas posteriores. Pode-se notar a presença de novos loteamentos que mostram uma cidade ultrapassando o triângulo histórico e as limitações que os rios e as várzeas impunham.
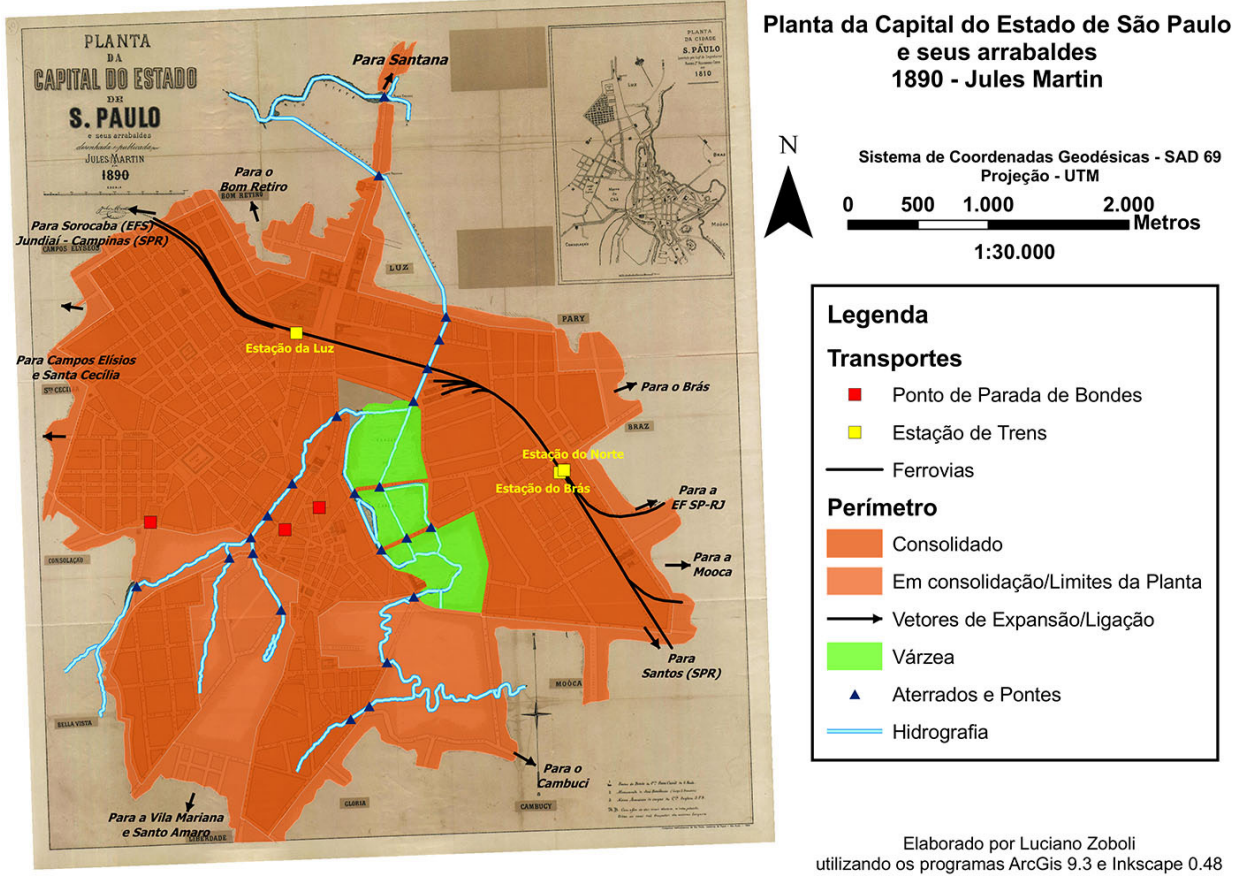

Figura 6 - São Paulo em I890

Para o mapa da figura 6 a referência foi um mapa histórico produzido em $1890^{60}$ por Jules Martin.

No mapa de I890 representam-se áreas que ultrapassam o centro histórico da cidade, e que vão para além das ferrovias. Áreas como Mooca, Santa Cecília, Bela Vista estão assinaladas. A hospedaria dos imigrantes surge no mapa ao lado da ferrovia Santos-Jundiaí, o que mostra a importância da imigração na cidade e dá uma ideia

58 REIS FILHO, Nestor Goulart, op. cit., 2004.

59 Sobre a importância dessa planta Eudes Campos informa que, em 7 de março de I88I, um vereador indicou à Câmara que solicitasse à empresa cópia desse documento gráfico para que fosse realizado a partir dela um trabalho de complementação de dados que interessava à municipalidade. Eudes Campos apud GOUVÊA, José P. Neves, op. cit., p. I03.

60 KAKO, Iara Sakitani, op. cit. 
da dinâmica que a cidade vivia. Três linhas férreas estão representadas: Sorocabana, Santos-Jundiaí e Central do Brasil. Nele há uma tentativa de racionalizar um pouco a cidade na representação - ruas e quadras dentro de um "modelo" e a constituição de uma cidade enquanto bloco contínuo, mas que na verdade era descontínua, com alguns vazios próximos ao centro.

O novo mapa que resultou da vetorização representa em destaque as ferrovias e as estações, assim como os pontos de parada de bondes. Mais uma vez explicita e distingue as áreas de urbanização consolidada e as em consolidação, e do mesmo modo atualiza os vetores de expansão e de ligação. Percebe-se que a representação da cidade começa a demonstrar por quais caminhos ela se consolidaria e como as ferrovias foram decisivas na criação de novos espaços (sobretudo nas várzeas) urbanos que viriam a se integrar na cidade. Nesse caso a rede de bondes não terá o mesmo peso que as ferrovias em razão de estar muito circunscrita à área central da cidade.

Já o mapa da figura 7 representa uma síntese que permite uma comparação das áreas que constam nos mapas de I877, I88I e I890, agora com o acréscimo de um mapa produzido em I897, que pertence ao segundo grupo de mapas selecionados. Esse mapa foi elaborado considerando as fontes cartográficas sob o mesmo referencial geodésico, sobre uma base geoespacial dos distritos de São Paulo do ano 2000.

Antes da interpretação do mapa de síntese da figura 7 é importante trazer algumas informações sobre esse mapa histórico de I897, pois sua presença na síntese vai promover um verdadeiro choque visual e gerar dúvidas interessantes sobre a evolução da urbanização da cidade. Denominado Planta geral da capital de São Paulo, foi realizado por Gomes Cardim e, de acordo com Nestor Goulart Reis Filho ${ }^{6 \mathrm{I}}$, será o mais completo mapa da cidade de São Paulo no século XIX. Inclui uma área muito mais extensa que os anteriores incluindo os loteamentos a oeste (V. Buarque, Santa Cecília, Higienópolis, Av. Paulista) e as áreas urbanizadas ao longo das várzeas e das estradas de ferro (Lapa, Barra Funda, Bom Retiro, Pari, Brás, Mooca, Ipiranga), dominadas por fábricas e armazéns, elementos dos bairros operários que viriam abrigar a população trabalhadora paulistana ${ }^{62}$. Nesse mapa estariam traduzidos os esforços de racionalização acerca do mapeamento do município para além do centro pioneiro ${ }^{63}$.

A extraordinária ampliação da área representada nesse mapa foi atribuída pelos pesquisadores do presente a uma correspondente ampliação da área urbanizada da cidade. Eudes de Campos ${ }^{64}$ adere ao "discurso" do mapa entendendo que os novos loteamentos desenvolvem-se para atender uma população que saltou de 65.000

6I REIS FILHO, Nestor Goulart, op. cit., 2004.

62 A ocupação dessas regiões tão díspares implicou um caráter descontínuo da cidade, sendo a sua estrutura urbana caracterizada por um núcleo densamente ocupado cercado por grandes espaços vazios. Junto das linhas de trem, bairros desligados do centro pioneiro.

63 ACKEL, Luiz; CAMPOS, Candido Malta. Antecedentes: a modernização de São Paulo. In: SOMEKH, Nádia; CAMPOS, Cândido Malta (Org.). A cidade que não pode parar: planos urbanísticos de São Paulo no século XX. São Paulo: Mackpesquisa, 2002.

64 Eudes Campos apud GOUVÊA, José P. Neves, op. cit., p. I3I. 
habitantes em I890 para 240.000 em I900. Estaria aí a explosão urbana que o mapa registra. Ocorre que o mapa tinha "vida própria" e representou loteamentos e áreas praticamente vazias, desintegradas da cidade naquela época. Nalguma medida, talvez esse mapa invente ou antecipe uma cidade, mas com mais certeza pode ser dito que ele inventa a futura cartografia da cidade, pois os mapas posteriores vão tê-lo como referência ${ }^{65}$.

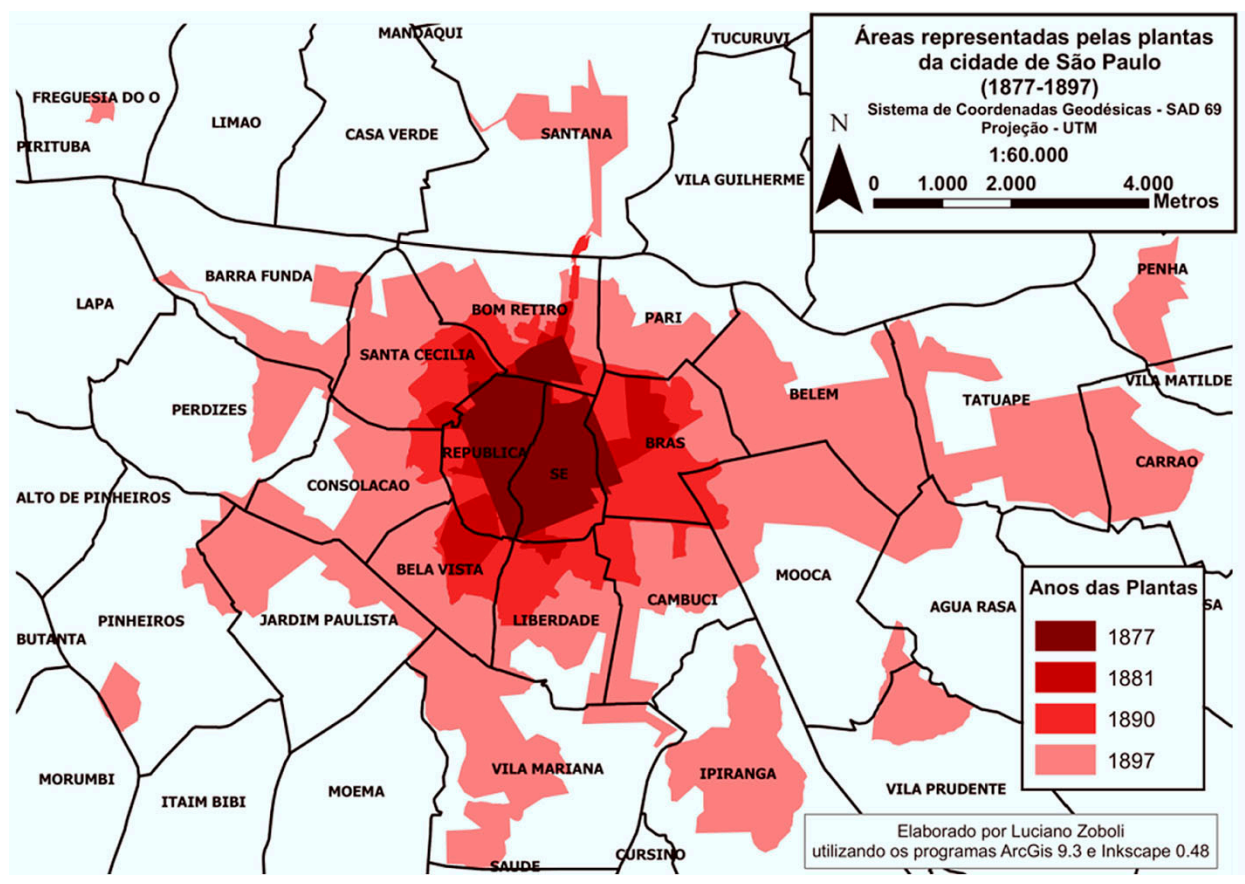

Figura 7 - Áreas representadas pelas plantas da cidade de São Paulo (I877-I897)

O mapa de figura 7 é uma síntese de quatro representações da cidade. Trata-se de uma visualização nova. Aqui é forçoso advertir que, mais que uma evolução da urbanização da cidade, ele representa e contrasta as formas cartográficas de representar a cidade, contendo certa subestimação do espaço da cidade nos mapas de I877, I88I e I890, e uma representação criativa superestimada que levou a cidade para onde ela ainda não havia ido. Nos sete anos que separam o mapa de I89o do de I897 não houve toda a expansão visualizada na síntese da figura 7. De todo modo, observa-se algo de uma cidade fragmentada de espaços descontínuos.

Já os novos mapas das figuras 8, 9 e Io apresentam a evolução da rede de

65 Para uma análise do papel operador desse mapa, ver artigo de Eliane Kuvasney publicado neste dossiê. Ver também: SIMONI, Lucia Noemia. A planta da cidade de São Paulo de I897: uma cartografia da cidade existente ou da cidade futura?. In: SIMPÓSIO LUSO-BRASILEIRO DE CARTOGRAFIA HISTÓRICA, 3., 2009, Ouro Preto. Anais... Disponível em: <https://www.ufmg.br/rededemuseus/crch/simoni_a-planta-da-cidade-de-sao-paulode-I897.pdf >. Acesso em: 20 jun. 2016. 
transportes, conforme a cronologia dos mapas escolhidos (segundo grupo), incluindo a aplicação de elementos vetorizados a partir de fontes bibliográficas.

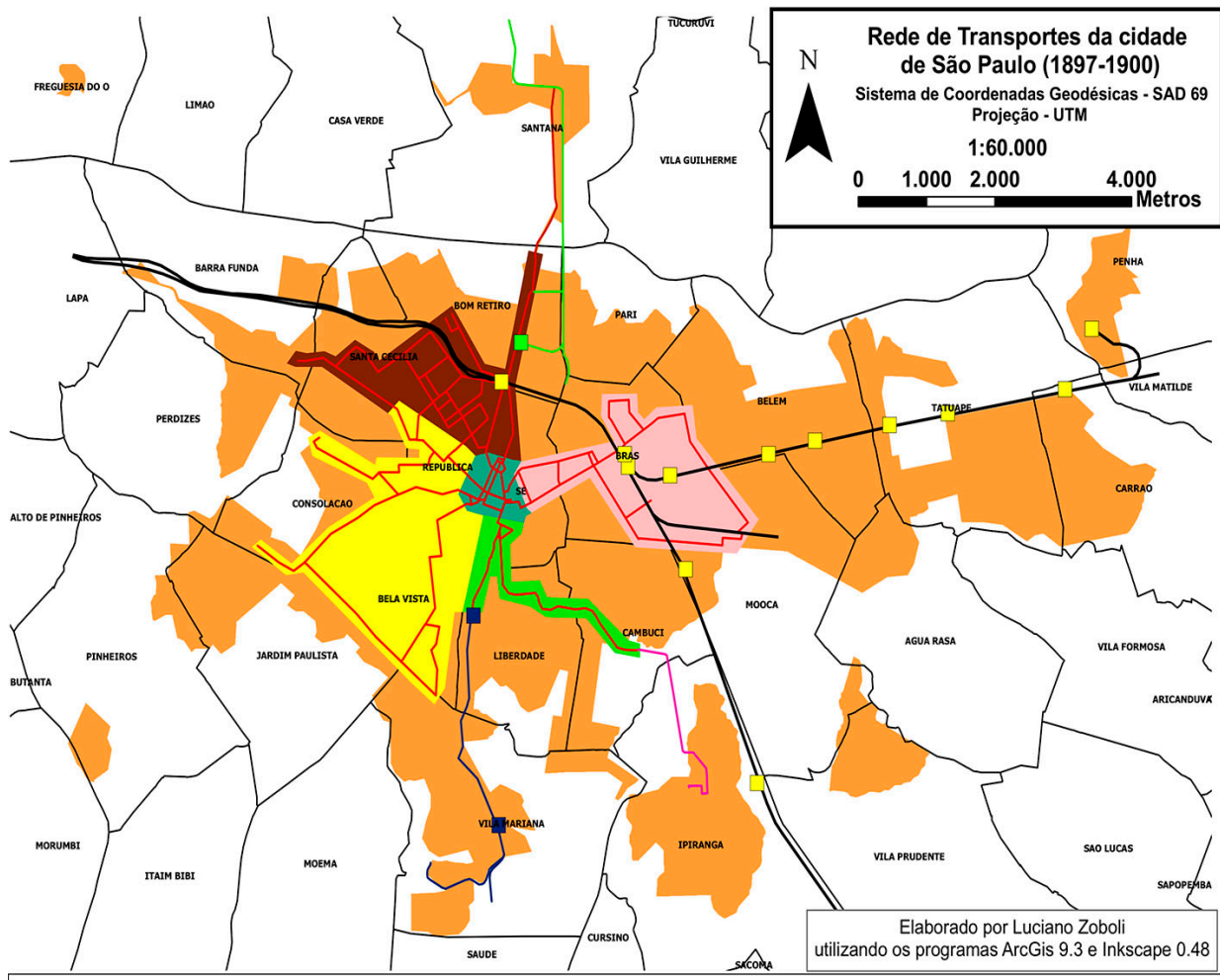

\section{Legenda}

\section{Transportes}

Estação de Trens

Estação de Tramways (Cantareira)

- Estação de Tramways (S. Amaro)

- Ferrovias

- Tramway Cantareira

—— Tramway S. Amaro

— Tramway Ipiranga
_ Linha de Bondes - CVP

_L Linha de Bondes - Santana

\section{Seções - CVP}

Santa Cecília
Brás
Cambuci
Bom Retiro
Área compartilhada pelas 4 seções

Figura 8 - Rede de transportes da cidade de São Paulo (I897-I900) - aproximação entre o mapa de Gomes Cardim (I897) e os dados fornecidos por Alfredo Moreira Pinto ${ }^{66}$

No mapa da figura 8 utilizou-se como referência o mapa de I897 de Gomes Cardim. Dele se vetorizou a rede de linhas de bondes por tração animal da Companhia Viação

66 PINTO, Alfredo Moreira. A cidade de São Paulo em I90o. São Paulo: Governo do Estado de São Paulo, I979. 
Paulista reconstruindo os percursos a partir do trabalho de Alfredo M. Pinto ${ }^{67}$ que se reporta à São Paulo de I900. Aqui existem apenas bondes a tração animal, que têm suas linhas restritas à área central da cidade, e o que articula a cidade para além do centro são as linhas de tramways e as ferrovias. De todo modo, as redes de transportes não são densas, mas é preciso ter em conta o que já foi abordado anteriormente sobre esse mapa de I897 que estava "exagerando" as dimensões da cidade.

O mapa da figura 9 vai se inserir na abertura do século XX e registrará uma importante novidade: a rede de bondes elétricos, que dará o tom da mobilidade urbana da cidade a partir daí. Num breve espaço de tempo essa rede irá substituir os bondes a tração animal. Ela foi instalada por uma empresa canadense que passaria a ter um peso enorme na história da cidade. Trata-se da The São Paulo Railway, Light and Power Co. fundada em 7 de abril de $1899^{68}$. A rapidez com que a Light implementou seus serviços na cidade de São Paulo demonstrava que havia demanda por meios de circulação que integrassem a cidade. Demonstrava também que São Paulo tinha tamanho e riqueza suficientes para estimular esse ramo da economia urbana.

A primeira linha de bonde foi inaugurada no dia 7 de maio de I90o. Roberto P. Toledo relembra o registro desse dia visto por Jorge Americano:

Naquela manhã de sol, veio gente das ruas vizinhas e muita gente de longe. Inauguravase a primeira linha, entre o largo de São Bento e o fim da Barão de Limeira (Chácara do Carvalho). Linha da "Barra Funda". Carros abertos de nove bancos [...]. Na direção do bonde, o conselheiro Antônio Prado, prefeito da cidade ${ }^{69}$.

Numa rápida comparação com o mapa da figura 8 pode-se notar a extraordinária densificação da rede de bondes representada no mapa da figura 9, que se reporta a I905, e no mapa da figura Io, relativo a I9I4.

\footnotetext{
67 Ibidem.

68 Fundada por William Mackenzie, auxiliado por seu filho Alexander Mackenzie. Juntaram um grupo de investidores em Toronto para a viabilidade financeira do negócio e, para a viabilidade técnica, recrutaram o engenheiro americano Frederick Pearson, diretor de grandes empresas ligadas ao transporte sobre trilhos, inclusive a companhia de bondes de Nova York. TOLEDO, Roberto P., op. cit.
}

69 Ibidem, p. 33 


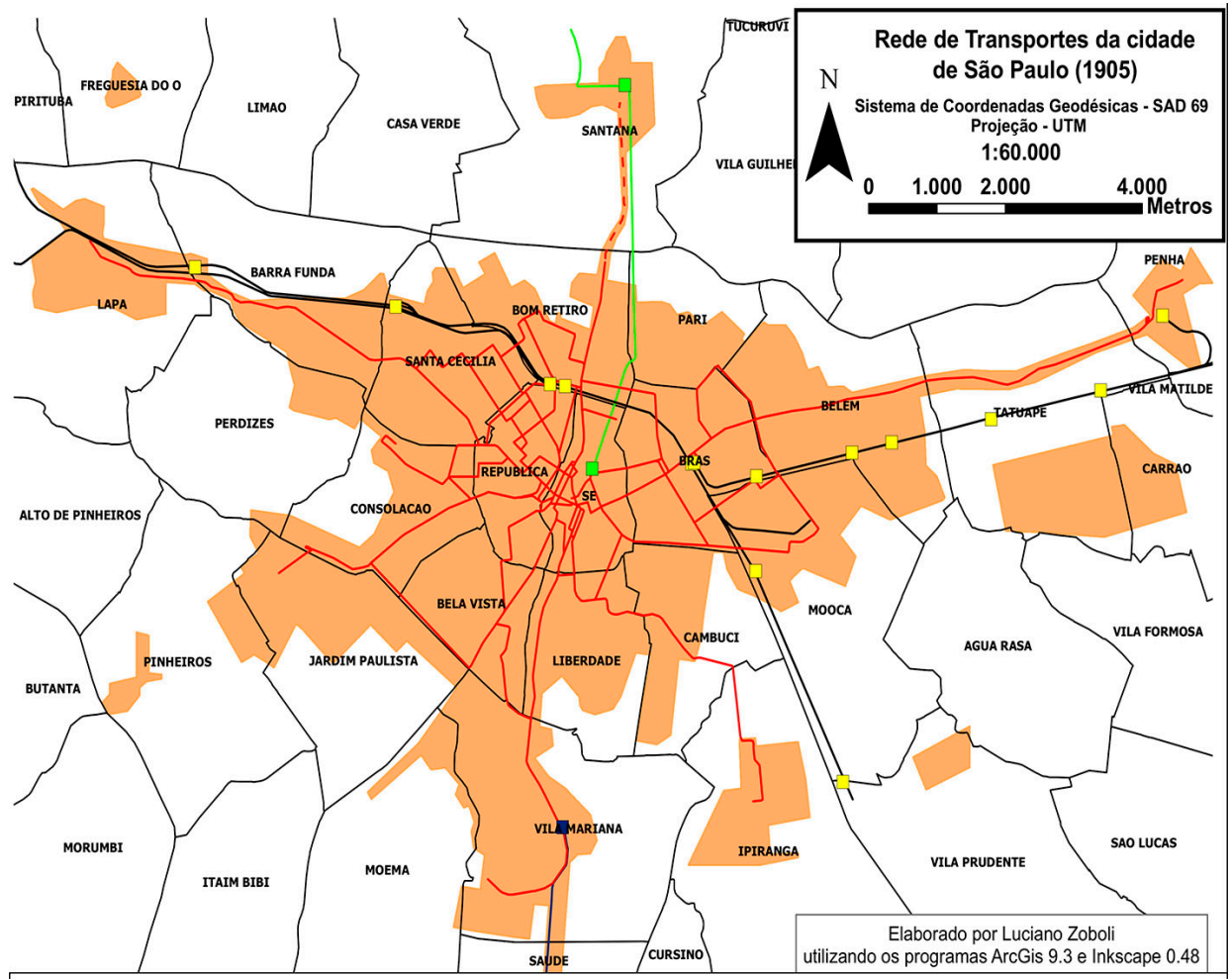

\section{Legenda}

\section{Transportes}

Estação de Trens
Linha de Bondes

- - - Linha de Bondes (tração animal)

\section{Estação de Tramways (Cantareira) Perímetro}

- Estação de Tramways (S. Amaro)

Representado pela Planta

Ferrovias

Distritos de São Paulo (2000)

\section{Tramway Cantareira}

Tramway S. Amaro

Figura 9- Rede de transportes da cidade de São Paulo (I905) 


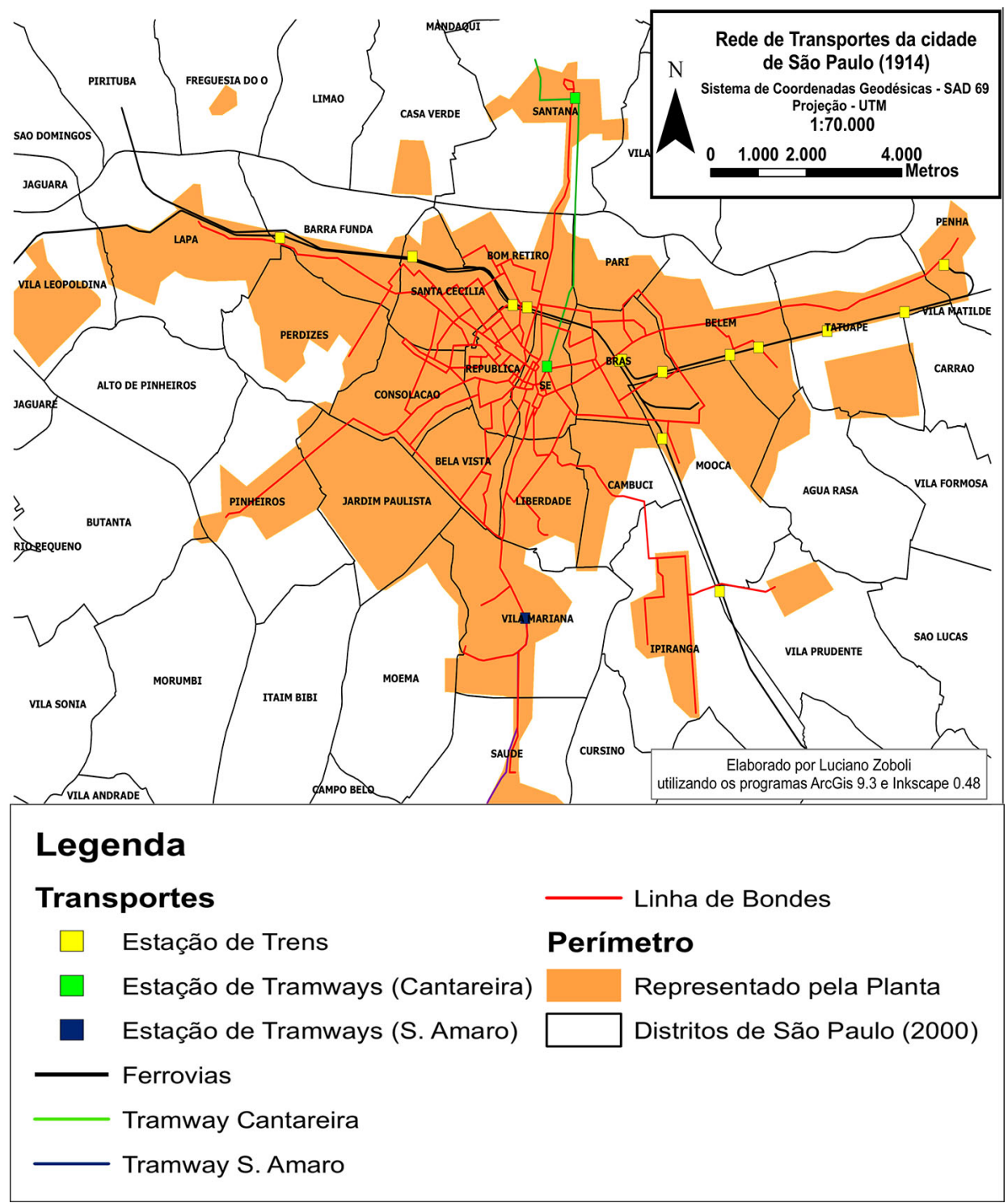

Figura Io - Rede de transportes da cidade de São Paulo (I9I4)

O mapa da figura 9 foi feito a partir do mapa histórico de I905. A fonte para os elementos vetorizados foi Stiel70. Dela se extraíram os itinerários para se chegar à rede, cotejando com o que já estava presente no mapa histórico.

Embora haja ainda prevalência da rede de bondes no centro e no vetor oeste, que são as áreas mais "nobres" da cidade na época, no novo mapa nota-se que as linhas de bonde se estendem para zonas da cidade que ultrapassam de longe o centro da cidade

70 STIEL, Waldemar Correa, op. cit. 
deixando para trás o período dos bondes movidos a tração animal que não podiam ousar em tais distâncias.

O mapa da figura Io também teve seus elementos vetorizados de Waldemar Stiel ${ }^{1 \mp}$. Os itinerários das linhas foram comparados com o que mapa já continha. Nessa data (I9I4) o recorte do mapa teve que ser mais amplo para dar conta do crescimento da cidade. Nele se percebe o aumento da densidade da rede e a integração de algumas áreas que estavam "desconectadas" em I905, como Vila Prudente e Pinheiros.

$O$ processo de densificação da rede de bondes (com as ferrovias e os tramways ${ }^{72}$ ) que os mapas mostram, mais que um simples crescimento de uma infraestrutura urbana, conduz à reflexão sobre o processo de constituição da cidade. Áreas que apareceriam anteriormente desconectadas nos mapas do século XIX nos mapas das figuras 9 e Io aparecem integradas. E nem sempre tinham linhas de bonde porque se integraram à cidade, mas, ao contrário, foram integradas pelas linhas de bonde. Não são raros os casos nos quais as propagandas dos loteamentos, quer dizer de áreas ainda despovoadas, anunciavam o serviço de uma linha de bonde que articularia o loteamento ao conjunto da cidade. Esse é o caso, por exemplo, de alguns loteamentos realizados pela Cia. City.

Uma testemunha estrangeira relata que no período retratado pelos mapas "a cidade possui, por um lado, um bom serviço de bondes, cuja rede percorre toda a cidade e sua vizinhança, graças à qual não é difícil visitá-la em seus vários pontos e percorrer parte dos seus arredores" 73 . Isso são impressões de um estrangeiro, que talvez tenha ficado surpreendido em encontrar o que não esperava. Mas a população da cidade (o usuário constante da rede de bondes) não comungava necessariamente essa visão benigna do sistema de transportes. Demonstração disso são as reclamações frequentes contra a Light em relação à qualidade de seus serviços.

De todo modo, a rede, tal como se encontrava, representava uma possibilidade razoável do paulistano em se deslocar pela cidade. Jacques Lévy destaca que, enquanto possibilidade, a mobilidade considera a capacidade de se mobilizar pela cidade em função da acessibilidade e da oferta de transporte ${ }^{74}$. E isso São Paulo possuía nalguma medida, porém tudo se complicará com o crescimento futuro da cidade.

7 I Ibidem.

72 O serviço de trens tornava São Paulo um dos principais entroncamentos ferroviários de ligação entre o interior e o litoral, enquanto o serviço de tramways integrava a capital a outros municípios vizinhos, como Santo Amaro e Guarulhos. Havia, portanto, uma centralidade e um protagonismo crescente para a Capital em relação ao afluxo de pessoas e produtos na dinâmica estadual e, posteriormente, nacional.

73 Alfonso Lomonaco. In: PASSOS, Maria L. Perrone; EMÍDIO, Teresa. Desenhando São Paulo: mapas e literatura - I877-I954. São Paulo: Senac/Imprensa Oficial, 2009, p. 42.

74 LEVY, Jacques. Os novos espaços da mobilidade. In: GEOgraphia, Revista da Pós-graduação em Geografia da Universidade Federal Fluminense - UFF, v. 3, n. 6. Niterói/ RJ, UFF/EGG, 2002, p. 7-I7. Disponível em: <http:// www.uff.br/geographia/ojs/index.php/geographia/article/viewFile/62/60 >. Acesso em: II jul. 20I4. 


\section{MaPas de São PaUlo: distânCia-Custo e distânCia-Tempo}

Os mapas anteriores deram visualização à rede de bondes 75 e permitiram observar a densificação da malha, a maior cobertura extensiva e a multiplicação de paradas e estações. Foram elaborados com um fundo de mapa euclidiano e são eficientes para o que se propõem. No entanto, há mais a ser aprofundado. E há, para tal, novos recursos cartográficos que possibilitam experimentos produtivos para as interpretações sobre a dinâmica da cidade de São Paulo no período.

Considerando a realidade atual de São Paulo fica fácil entender que espacializar as redes de transportes existentes e medi-las conforme suas distâncias em metros não basta para avaliarmos a eficiência delas. O que significa um percurso de metrô de $5 \mathrm{~km}$ e um percurso de ônibus de mesma distância para o usuário? Vários fatores podem dar conteúdos distintos a essa distância: linha reta e desobstruída, linhas obstruídas por congestionamentos e paradas obrigatórias podem interferir nos tempos e nos custos dos percursos. Por isso, parecem fazer sentido representações das redes de transporte na cidade atual com base na distância-tempo, ou com base em outras métricas como a distância-custo. Isso ajuda a esclarecer a lógica da cidade de hoje. Mas, em relação à cidade do início do século XX, usar outras medidas (de tempo e de custo, por exemplo) ajudaria a decifrar a cidade que se desenhava? Nosso estudo experimentou responder essa questão.

Em função da disponibilidade do banco de dados georreferenciados e do georreferenciamento relativo, o experimento pôde ser realizado produzindo uma representação da distância-custo em I905 e outras de distância-tempo em I905e I930, tendo essas métricas como fundos dos mapas.

Para começar o estudo, novos dados sobre a rede de bondes elétricos foram sistematizados e vetorizados. A fonte principal foi o trabalho de Waldemar Stiel ${ }^{76}$, do qual se extraíram itinerários e informações acerca dos custos, das velocidades e dos tempos dos percursos. Esses dados foram processados com o software IsoDistAngle ${ }^{77}$ e com o software Darcy ${ }^{78}$. Ambos permitem transformações cartográficas ligadas às distâncias e às direções de um local de origem para diversos locais de destino ${ }^{79}$. Os passos foram os seguintes:

\section{E também ferrovias e tramways.}

76 STIEL, Waldemar Correa, op. cit.

77 Para detalhes dos softwares ver: LOGICIEL de transformation cartographique unipolaire IsoDistAngle. Conception: Colette Cauvin; Réalisation: Gilles Vuidel, Strabourg, 20I3. Disponível em: <http://thema. univ-fcomte.fr/IsoDistAngle>. Acesso: 2 abr. 2014

78 CAUVIN, Colette. Logiciel de comparaison spatiale Darcy 2.o. Mode d'emploi. Paris: Besançon, Strasbourg, 2009. Disponível em: 〈http://thema.univ-fcomte.fr/images/Productions/ME_IsoDistAngle.pdf >. Acesso em: 20 jun. 2016.

79 Para outros detalhes ver CAUVIN, Colette. L'accessibilité intraurbaine: une approche méthodolohique. In : CAUVIN, Colette; REYMOND, Henri; KLEINSCHMAGER, Richard (Org.). L'espace géographique des villes. Paris: Anthropos, I998; DUTENKEFER, Eduardo. Métodos e metodologias para desvendar a acessibilidade do município de São Paulo, 20I4 (mimeo.). 
I) A partir da vetorização da rede de bondes elétricos feita sobre o Sara, selecionaram-se pontos de controle referentes ao itinerário dos bondes - origem, pontos médios ${ }^{80}$ e destino. Cada ponto teve sua coordenada de latitude e longitude registrada em uma tabela para a construção de um banco de dados. Os mapas das figuras II (I905) e I2 (I930) mostram o resultado dessa vetorização da rede e da seleção desses pontos de controle.
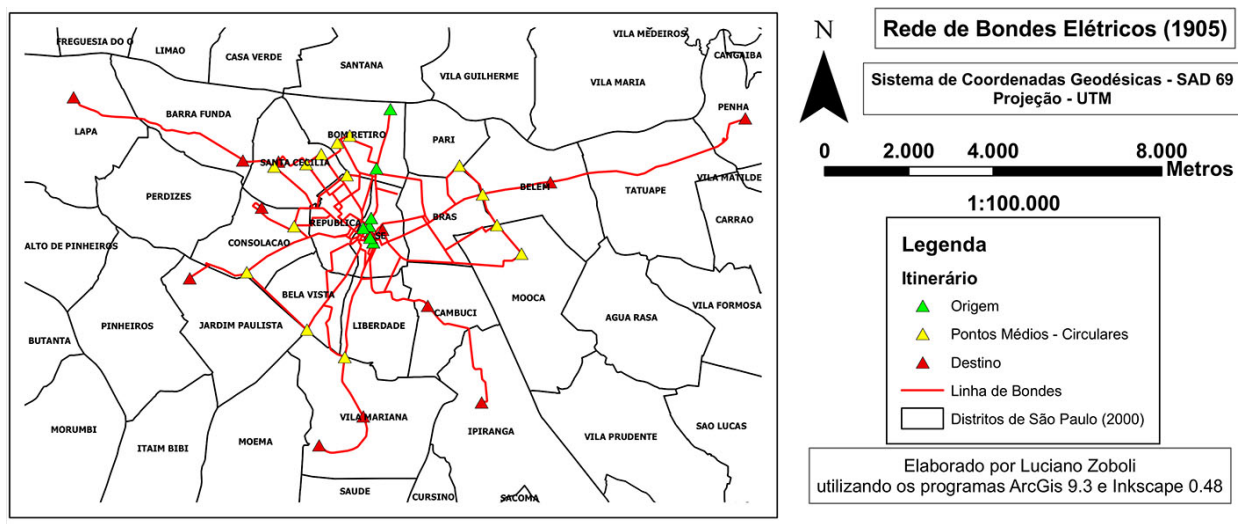

Figura II - Rede de bondes elétricos e pontos de controle (I905)

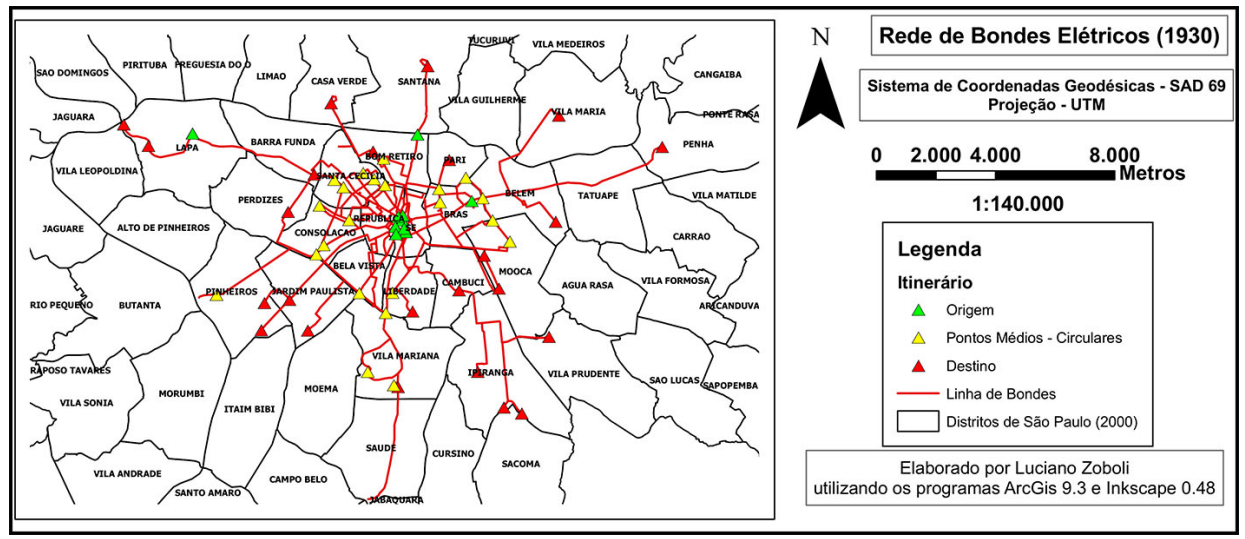

Figura I2 - Rede de bondes elétricos e pontos de controle (I930)

2) Com o levantamento dos pontos de controle, foi necessário uma referência central para o cálculo das distâncias para as novas métricas que seriam adotadas (custo e tempo). Em relação ao custo o ponto central para a análise entre a origem e os diversos destinos foi a esquina entre as ruas da Quitanda e do Comércio, local onde, segundo Stiel ${ }^{81}$, iniciava-se a delimitação das seções definidas como parâmetros para

80 Os pontos médios dizem respeito às linhas circulares e são equidistantes em relação à origem e ao destino. 8I STIEL, Waldemar Correa, op. cit. 
a cobrança dos preços diferenciados ${ }^{82}$. Já no que diz respeito ao tempo, tomou-se como ponto central a origem mais utilizada pelos bondes naquele ano ${ }^{83} \mathrm{e}$ o seu cálculo dependeu de uma aproximação das médias de velocidades para diversas regiões da cidade de acordo com a observação da estrutura da rede e pela comparação com parâmetros apresentados por Waldemar Stiel ${ }^{84}$.

3) Com as coordenadas dos pontos de controle e a definição dos pontos centrais, foram calculados o custo e o tempo de determinados trajetos entre o local de origem e os diversos destinos ${ }^{85}$.

4) As coordenadas e os dados de custo e tempo foram inseridos no IsoDistAngle, que forneceu as coordenadas homólogas para essas novas métricas de referência, gerando uma espécie de pontos-imagem relativos a esses novos olhares. A inserção das coordenadas de origem juntamente com as coordenadas desses novos pontos no software Darcy possibilitou a visualização das transformações cartográficas de posição diferenciais ou de comparação. Isso resultou nalgumas anamorfoses.

Os mapas das figuras I3, I4, I5, I6, I7 e I8 apresentam os resultados obtidos com o uso das métricas distância-custo e distância-tempo, tendo como objeto as redes de bondes identificadas nos anos de I905 e I930. Tendo em vista os mapas de 1905 das figuras I3 e I4, que tratam de representar a rede de bondes elétricos segundo a distância-custo, foi usado, como já dito, o método unipolar. Por esse método chegou-se aos vetores de deslocamento, que indicam a diferença entre o ponto em coordenada geográfica e o mesmo ponto em coordenada custo. Esses vetores estão representados no mapa da figura I3, que ainda mantém o fundo euclidiano com os círculos concêntricos aplicados.

82 A cobrança da passagem, com o contrato de unificação de 6 de julho de I90I, era feita por zonas de cobrança dos preços (200 réis cada zona). Partindo desse cruzamento, estabeleciam-se as zonas de acordo com círculos concêntricos de $3 \mathrm{~km}$ de raio. Dessa forma, a primeira zona estava inscrita no primeiro círculo, a segunda se encontrava entre 3 e $6 \mathrm{~km}$, a terceira entre 6 e 9 km, e assim por diante (200, 400 e 600 réis). Algumas linhas atuaram sob regime de exceção dessa regra e foram mudando de acordo com regulamentações impostas pela Light ao longo dos anos. Esse sistema perdurou até I909, ano de unificação das tarifas em 200 réis.

83 Em I905, utilizava-se como ponto central a Praça Antônio Prado. Em I930, utilizava-se o Largo São Bento. 84 A inspiração para a determinação das velocidades foi o artigo I5 do Ato 135 de 26 de agosto de I902, no qual a municipalidade estabelecia limites de velocidade nas diferentes áreas da cidade. As zonas de velocidade foram então adaptadas para I905: para a área das principais ruas do centro atribui-se a velocidade média de $8 \mathrm{~km} / \mathrm{h}$; para as áreas com densidade de rede considerável, com muitos cruzamentos, foi atribuída a velocidade média de Io $\mathrm{km} / \mathrm{h}$; para as demais áreas, a velocidade média foi de I2 $\mathrm{km} / \mathrm{h}$, com exceção das principais ligações com a periferia, onde havia grandes avenidas sem cruzamentos ou longos caminhos sem grande fluxo, nas quais a velocidade média era de I5 km/h. Em I930, seguiu-se a mesma lógica, mas com velocidades inferiores em função da densificação da rede e do aumento do tráfego: médias de 5, 8, II e I4 km/h, respectivamente.

85 Foram selecionados I7 destinos para o cálculo da distância-custo (I905), I9 para o cálculo da distância-tempo (I905) e 24 para o cálculo da distância-tempo (I930). 


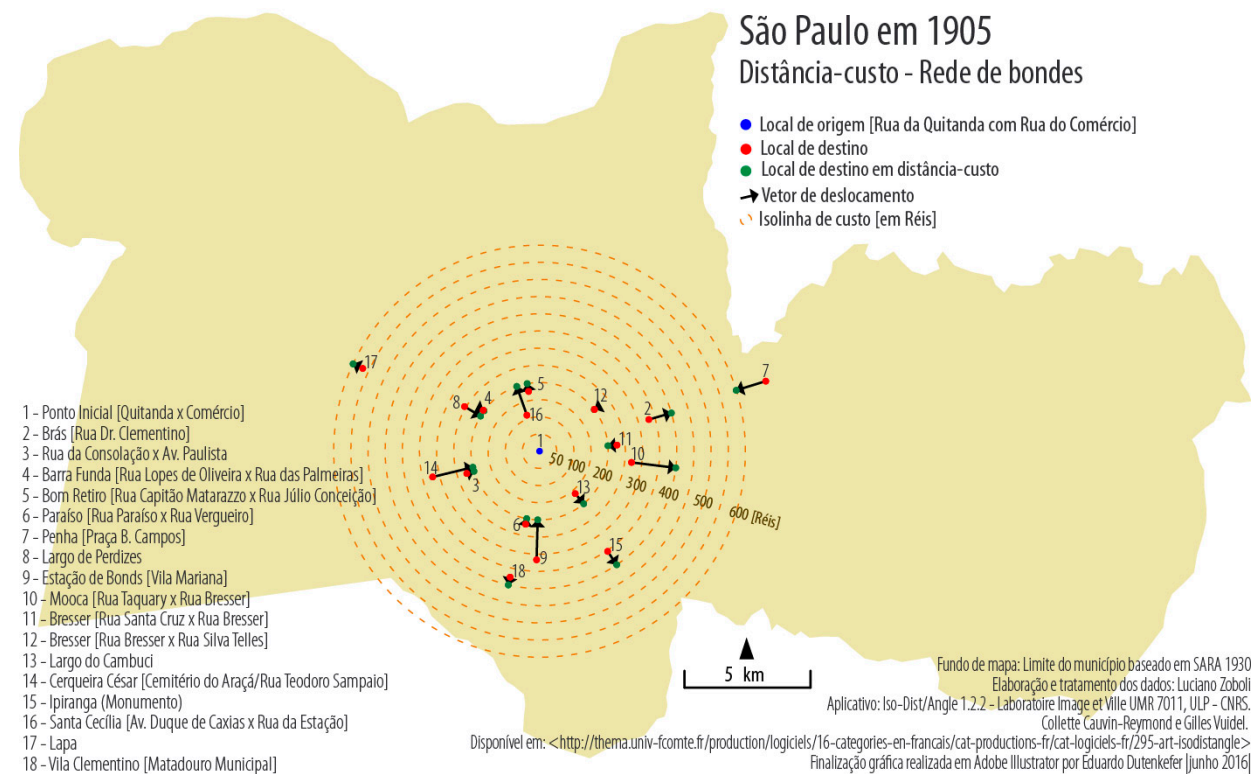

Figura I3 - Mapa de distância-custo em métrica euclidiana da rede de bondes em I905

Para interpretar o significados dos vetores nesse mapa, serão utilizados dois destaques. A chave é chegar aos valores que deveriam ser cobrados pela distância percorrida do ponto central ao seu destino.

O primeiro exemplo é o do local I4, Cerqueira César. Nota-se que o vetor é atraído para o centro (quer dizer, no mapa de I905, esse local aparece mais próximo do centro) e sua ponta se situa no círculo concêntrico que compreendia a seção de 200 réis. No entanto, segundo a sua posição notada (ponto em vermelho - local de destino) no mapa atual referenciado (figura I3) a tarifa deveria ser de 320,64 réis (no círculo entre 300 e 400 réis). Outro exemplo é o local I6 (Santa Cecília). Nesse caso, o vetor se afasta do centro, quer dizer: no mapa de I905 esse ponto aparece mais longe do centro do que ele está no mapa atual referenciado (figura I3). Por estar mais afastado, esse ponto cai no círculo concêntrico de 200 réis, mas deveria ser III,07 réis.

Definindo a lógica nesse mapa: os locais onde os vetores são atraídos para o centro deveriam pagar mais pela distância que percorreram, ao contrário, os locais nos quais os vetores se afastam do centro deveriam pagar menos pela distância percorrida. 


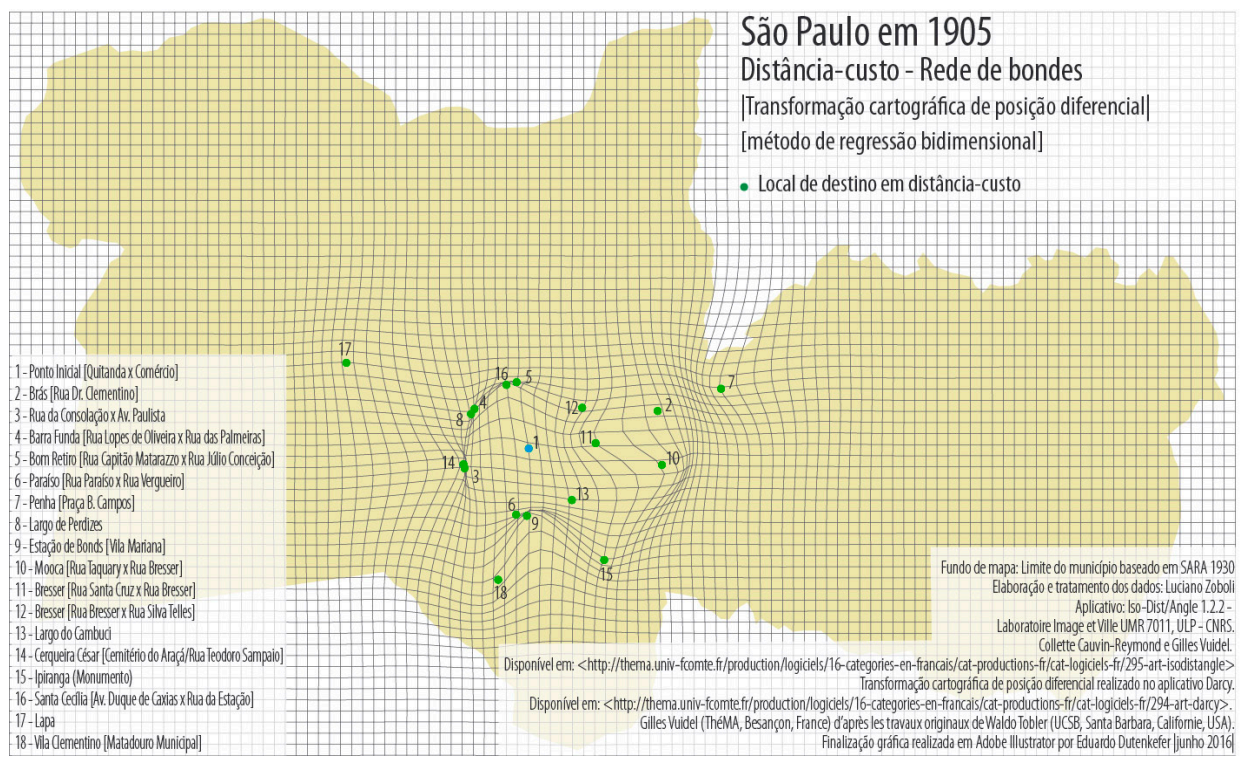

Figura I4 - Mapa de distância-custo em métrica não euclidiana da rede de bondes em 1905

Por sua vez o mapa da figura I 4 é uma anamorfose produzida pelo software Darcy utilizando o método de regressão bidimensional ${ }^{86}$. Só há transformações nas áreas de concentração de rede de bondes. Boa parte do município não sofre alterações porque a rede não $o$ atinge.

Trabalhando com os mesmos exemplos do mapa anterior, verifica-se que no local I4 (Cerqueira César) o grid se contrai. Quando o grid se contrai, significa que o valor cobrado era menor (no caso 200 réis), mas deveria ser cobrado mais (no caso 320,64 réis). No local I6 (Santa Cecília) o grid se expande, o que indica que o valor cobrado era maior (no caso, 200 réis) do que deveria ser (no caso III,07 réis). Fixando a regra: quando os grids se contraem, trata-se de uma posição em que se deveria pagar mais pela distância percorrida, e nos locais onde os grids se expandem, deveria se pagar menos pela distância percorrida.

Se tivermos em conta que o custo é um dos elementos definidores da acessibilidade, é correto dizer que a rede de bondes oferecia viagens mais "acessíveis" do que deveriam ser em termos de distância-custo e outras mais "restritivas". Isso que os mapas nos mostraram é um meio para indicar algumas lógicas imperantes na cidade naquele momento. Um exemplo interessante é o de Cerqueira César. Foi visto que a tarifa de bonde nesse ponto era de 200 réis, mas que deveria ser cobrado 320,64 réis. Uma razão dessa situação é que Cerqueira César situava-se numa lista de locais que, a despeito de ultrapassarem a circunferência da primeira zona, permaneciam como

86 Método desenvolvido por Waldo Tobler. Para detalhes do método, ver : CAUVIN, Colette. Une methode generale de comparaison cartographique: la regression bidimensionnelle. Travaux et recherches, Fascicule 4. Strasbourg: UER de Geographie, Universite Louis Pasteur/ERA. 2I4 CNRS, I984. 
pertencentes à zona de 200 réis por decreto ${ }^{87}$. Por que a empresa (Light) criou exceções na cobrança das tarifas? Será porque algumas dessas áreas eram habitadas por classes sociais de mais poder político? Ou porque se tratava de localidade de grande afluxo e a tarifa, mesmo reduzida, compensava? Ou então: porque haveria interesses imobiliários, aos quais a Light estava associada e daí a maior acessibilidade? A cartografia proposta neste estudo ajuda a interrogar qualificadamente a história da cidade.

Em termos gerais a análise acerca da distância-custo (I905) demonstra que sua lógica segregava as áreas periféricas. Algumas localidades chegavam a ter uma tarifa três vezes mais elevada do que a relativa ao deslocamento para o espigão da Av. Paulista. Para os habitantes desses bairros periféricos, o custo pesava bem mais que o tempo de deslocamento.

Poderia se pensar que o experimento com distância-custo fazia sentido apenas numa cidade onde o preço da passagem do bonde não era uniformizado, e que, com a uniformização para qualquer distância, a distância-custo deixou de ser relevante. Isso não é verdade nem para a cidade atual, pois os custos de deslocamento não são uniformes (embora se tenha no interior do município de São Paulo um único valor de passagem de de ônibus). Há outros fatores que geram os custos diferenciais, tais como os deslocamentos intermunicipais ${ }^{88}$, a necessidade dos usuários de usar mais que uma condução, de complementar seus percursos alternando os meios etc. Quer dizer: seria fascinante, numa cidade complexa como São Paulo, criar uma cartografia contemporânea usando a distância-custo.

Os mapas a seguir (presentes nas figuras I5, I6, I7 e I8) trabalham com a distância-tempo em dois momentos - anos de 1905 e de I930. É evidente que a forma de vivenciar os espaços de nossas vidas, de percebê-los, passa pela forma de medi-los. Ou, de outra maneira: a forma de vivenciar, de perceber o espaço é expressa por formas de medi-lo. Assim como o espaço, o tempo não é uma realidade abstrata ${ }^{89}$. Por isso, tentar medir o espaço com critérios de tempo, isto é, operar com a distância-tempo reveste-se de complexidade que não é fácil controlar, especialmente quando estamos lidando com um tempo do passado, como no caso do início do século XX na cidade de São Paulo. Um autor importante nesse estudo, Waldemar Stiel, ao se referir ao tempo de espera dos bondes nos pontos em I90I, assim se manifesta:

87 O decreto definia que, para efeito de cobrança do preço de passagens, consideram-se como constituindo uma só seção, a despeito de ultrapassarem a circunferência da primeira zona, os seguintes trechos de linha: I) nas linhas do Brás e da Penha até a Rua Saldanha Marinho; 2) na linha do Hipódromo até o Hipódromo; 3) na linha da Liberdade até a Ponte Grande; 4) nas linhas da Barra Funda e Água Branca até a Capela de Perdizes; 5) na linha de Vila Cerqueira César até o Cemitério do Araçá. STIEL, Waldemar Correa, op. cit., p. I39 e I4I.

88 Afinal, a verdadeira cidade de São Paulo na qual seus habitantes se deslocam é composta por vários municípios.

89 Não só quanto ao conteúdo, mas quanto ao que opera. Pode-se dizer que uma dada região da cidade estará mais integrada ao conjunto quanto mais rápida for a interligação com o centro, por exemplo. Isso independente da distância em metro, que não é relevante em todas as situações. Bairros distantes, mas servidos por linhas do metrô (distância-tempo menor e mais estável) estão mais integrados às cidades que outros mais próximos, porém servidos por transportes mais lentos e irregulares. 
Os minutos acima mencionados [ele se refere a uma tabela] referem-se ao tempo de espera entre um bonde e outro. Havia certas linhas, como a da Água Branca e do Araçá, cujo tempo de espera era de desespero, apesar de, naquela época, o tempo poder ser esbanjado à vontade ${ }^{90}$.

O que seria um tempo de desespero se as pessoas tinham tempo para esbanjar? Esbanjar seria gastar o tempo de forma inútil? Interrogações sobre o tempo numa cidade não se desvinculam de suas lógicas materiais e imateriais, do seu modo de vida. De todo modo, algo seguro é afirmar que as pessoas pensam cotidianamente as distâncias espaciais em termos de tempo, nos termos como elas valorizam os seus tempos. Trabalhar com distância-tempo implica lidar com essas valorações. Com as representações feitas, algumas reflexões sobre a dinâmica da cidade do início do século serão acrescentadas a partir do trabalho com a distância-tempo.

No mapa de I905 da figura I5, aplicando círculos concêntricos como marcadores de zonas de tempo a partir de um ponto central, mapeou-se, sobre um fundo euclidiano baseado no Sara, I930 (georreferenciado com balizas geodésicas atuais), dados dos tempos de percurso de 20 pontos de destino em relação ao ponto central.

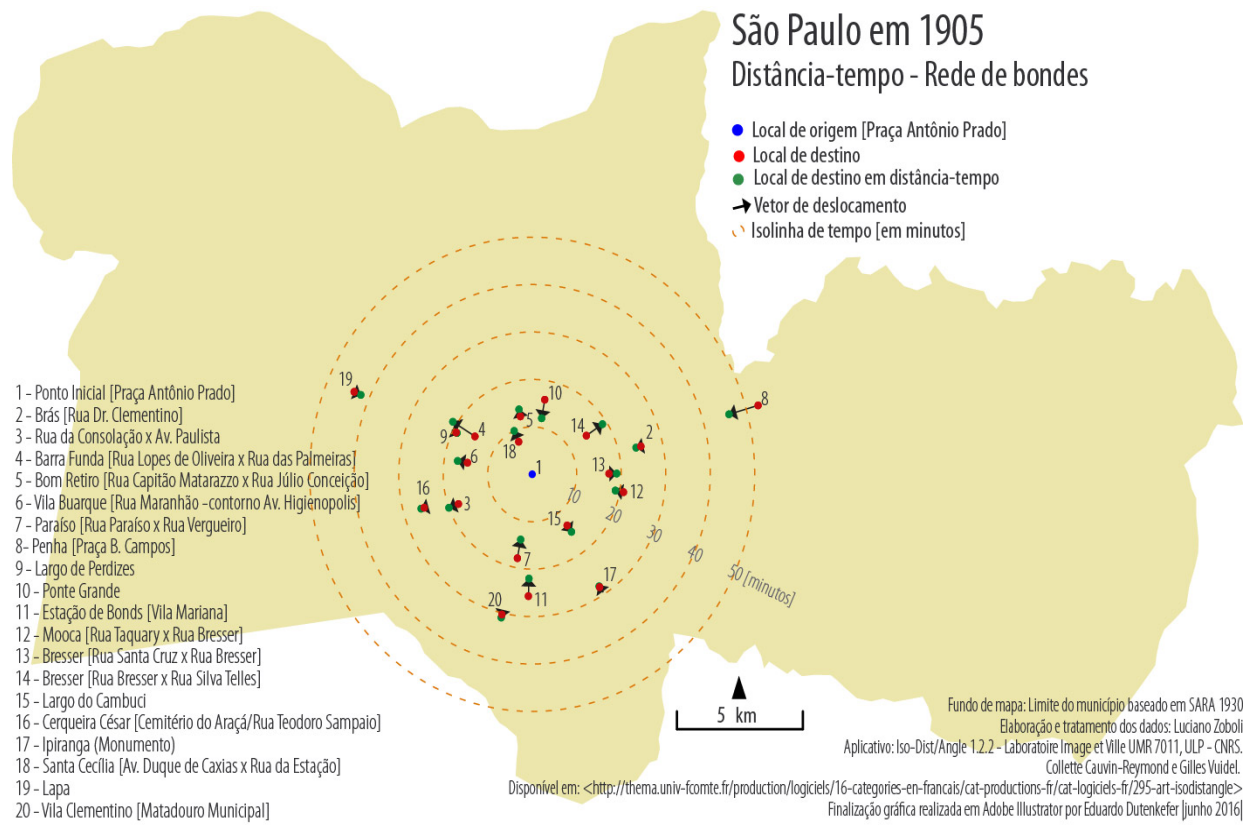

Figura I5 - Mapa de distância-tempo em métrica euclidiana da rede de bondes em I905

Os tempos de percurso variavam conforme as zonas de velocidade de I905.

90 STIEL, Waldemar Correa, op. cit., p. I75. 
As velocidades mais baixas estavam no centro. No mapa foram assinalados os vetores de deslocamento, que projetam uma aproximação ou afastamento do ponto central em função do tempo calculado de trajeto. Se se aproxima, ele leva menos tempo que levaria caso o deslocamento na cidade fosse numa proporção perfeita, representada pelos círculos concêntricos. Se se afasta, leva mais tempo nesse mesmo cenário. Exemplo: no ponto 7 (Paraíso) o vetor de deslocamento dirige-se ao centro. Nesse, a distância-tempo é menor que a média apresentada pela rede no acesso ao ponto central. Já no ponto I4 (Bresser) o vetor se desloca em direção à periferia. demonstrando que, apesar de o ponto estar próximo do centro em termos euclidianos, gasta-se mais tempo do que a média apresentada pela rede no acesso à Praça Antônio Prado (ponto central).

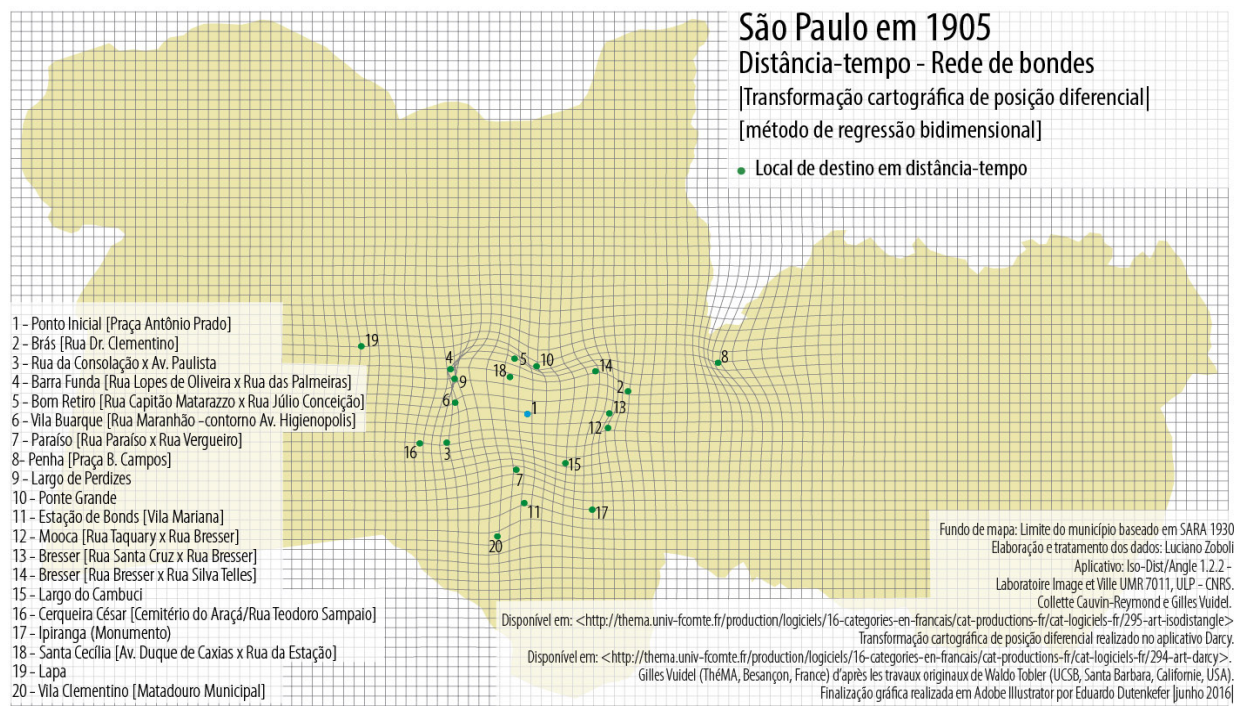

Figura I6 - Mapa da distância-tempo em métrica não euclidiana da rede de bondes em 1905

No mapa da figura I6 aparece uma anamorfose que se visualiza no segmento onde o grid está alterado (onde a rede de bonde se situava realmente de forma densa). Tomando novamente como exemplo o ponto 7 (Paraíso), nota-se uma contração do grid, indicando que, quando consideramos o tempo de deslocamento em relação ao ponto central, há maior acessibilidade dessa região quando comparada à média da rede de I905. Já no caso do ponto I4 (Bresser), o sentido inverso com uma expansão do grid, evidenciando menor acessibilidade frente à Praça Antônio Prado, se tomarmos a média de tempo da rede.

Para I930 foram produzidas as mesmas modalidades de mapas para expressar as distâncias-tempo da rede de bondes elétricos. Algumas informações precisam ser consideradas. A rede aumentou consideravelmente no intervalo entre I905 e I930 - "a 
extensão da rede de bondes, no ano de I924, era de 266,50 km"9I. Considerando que a cidade atual possui 78,3 km de rede de metrô, realça-se a importância da rede bondes para a cidade na época.

Quanto às velocidades praticadas na rede em I930, seguia-se a mesma lógica de I905, que era a criação de zonas de velocidade, porém, como a cidade estava mais densa, em cada uma dessas zonas a velocidade era menor.

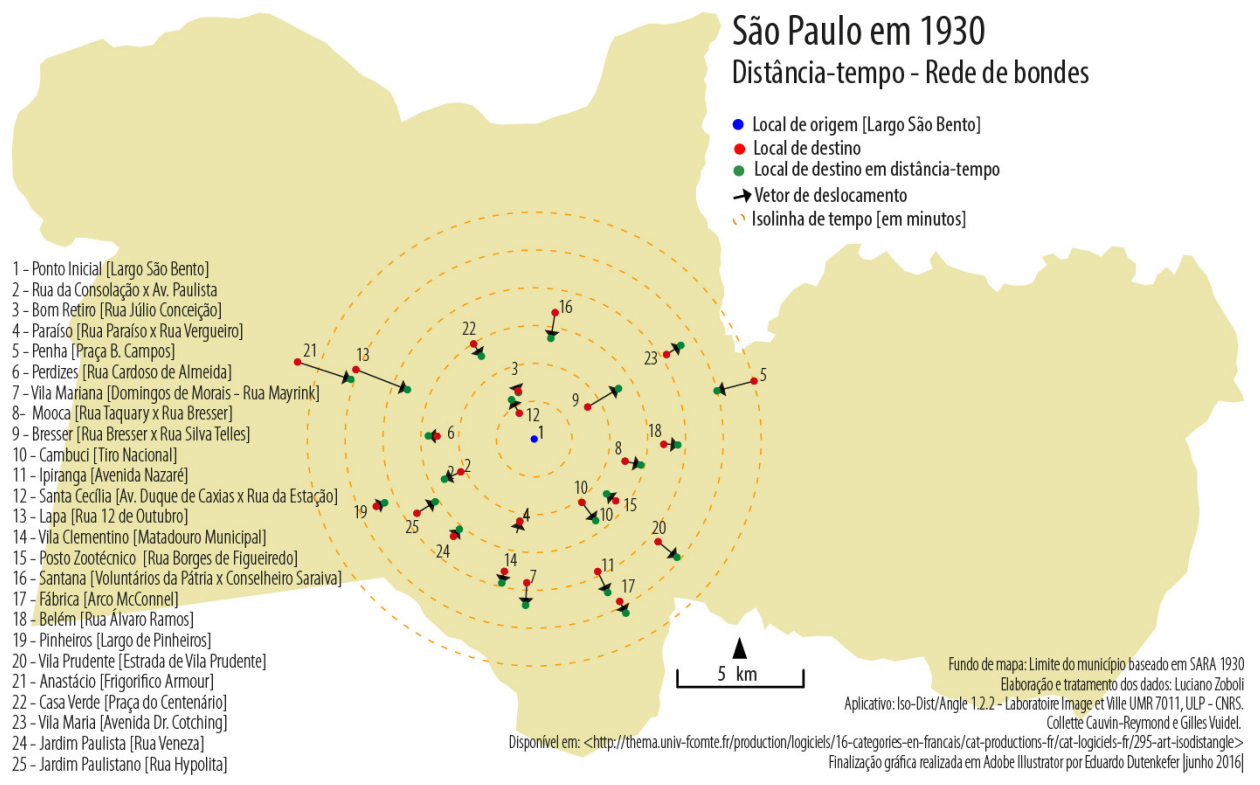

Figura I7 - Mapa de distância-tempo em métrica euclidiana da rede de bondes em I930

No mapa da figura I7 foram selecionados quatro pontos que vão servir de exemplo para a interpretação da representação. Os pontos 2I (Anastácio) e I3 (Lapa) têm seus vetores de deslocamento convergindo para o centro. Isso indica que em termos de acessibilidade eles se equiparam a áreas da cidade mais próximas ao centro, que, no entanto, são mais congestionadas e com os bondes mais limitados em termos de velocidade. Por sua vez, os pontos Io (Cambuci) e II (Ipiranga) têm seus vetores de deslocamento dispersando-se em relação ao centro. Direcionam-se para a periferia. Nessa direção havia um maior número de linhas e, por decorrência, maior densidade populacional que nos pontos 2I e I3. Isso implicava maior congestionamento, logo mais lentidão no deslocamento em relação ao ponto central. 


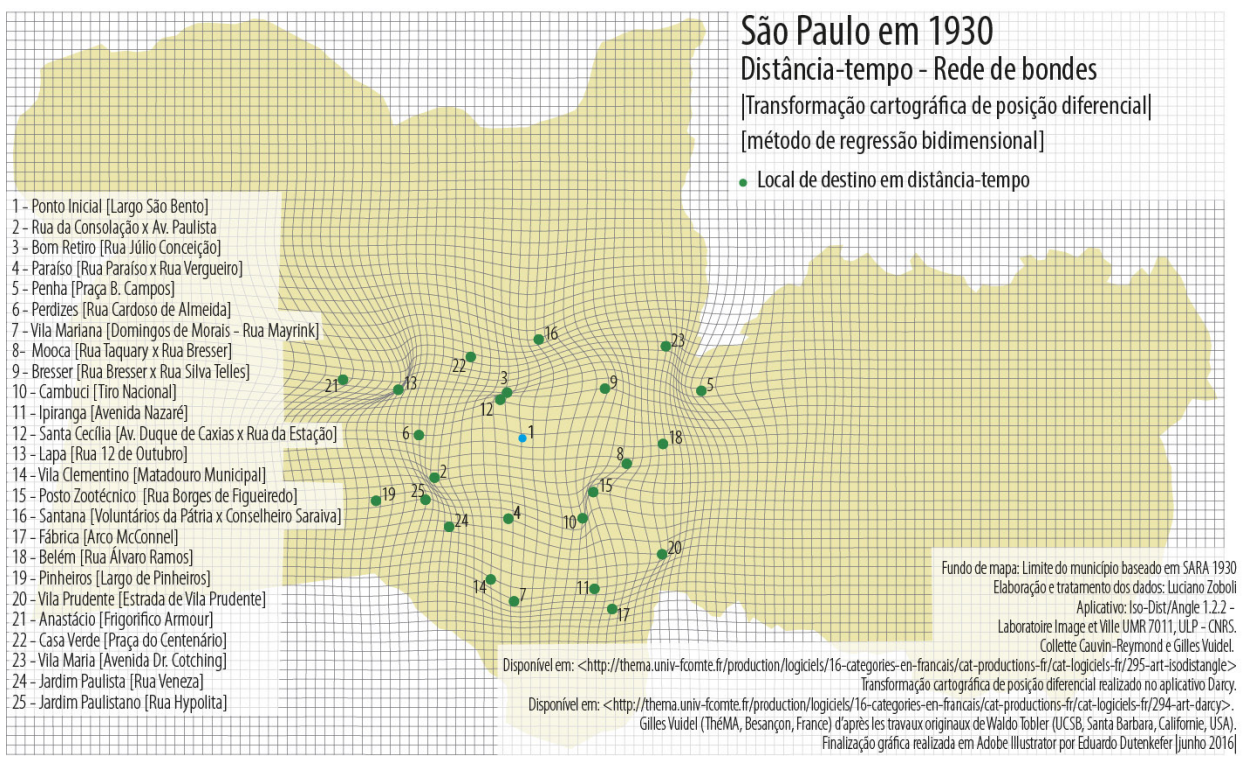

Figura 18 - Mapa da distância-tempo em métrica não euclidiana da rede de bondes em I930

O mapa da figura I8 segue a mesma lógica do mapa de I905. Trata-se de uma situação de transformação cartográfica (anamorfose) no segmento do município no qual a rede de bondes se estende. Percebe-se que as transformações abrangem uma área maior que a do mapa de I905. A rede de bondes cresceu. Nos pontos 2I (Vila Anastácio) e I3 (Lapa), nota-se uma contração do grid, indicando que o tempo de deslocamento frente ao ponto central (mesma referência para todos os pontos) é menor do que deveria ser. Logo, há maior acessibilidade dessa área quando comparada a toda a rede de I930. Já nos casos dos pontos Io (Cambuci) e II (Ipiranga) a lógica é inversa, pois há uma expansão do grid, evidenciando menor acessibilidade em relação à Praça Antônio Prado (ponto central).

Assim, os mapas de distância-tempo (I905 e I930) que usaram métricas não euclidianas (transformações cartográficas ou anamorfose) mostram em comum uma expansão (distensão) do grid a partir do ponto central. Algo que é um traço significativo da lógica de funcionamento desse sistema de bondes elétricos. As poucas opções para as áreas periféricas da cidade, além de evidenciarem a concentração de trilhos no centro e no vetor oeste de expansão da cidade, mostram como essa rede era intensamente usada no centro. Era um meio dominante, o que explica a presença das linhas circulares que ligam o "triângulo histórico" aos bairros de Santa Cecília, Consolação e, em menor número, Brás e Mooca. A extrema lentidão dos bondes na área central e a carência de linhas para as áreas de expansão, àquela altura de I930, mostram que São Paulo já não conseguia resolver os seus problemas de mobilidade.

De todo modo, o que, principalmente, deve ser ressaltado após a realização deste estudo é o fato de que as variadas representações bem observadas permitem muitas interrogações produtivas. Por exemplo: quais os critérios utilizados para priorizar 
a construção de alguns ramais (junto com os novos loteamentos) e como isso impulsionou o crescimento da cidade em algumas áreas? A rede de bondes teria sido um passo inicial da formação de uma cidade segundo o "modelo" radial-concêntrico? Essa rede teria contribuído para a formação de uma cidade com muita dependência do centro e com uma periferia desolada, sem urbanidade?

Comparando as escalas do espaço da cidade e sua infraestrutura de transportes entre 1930 os dias de hoje, percebe-se que a ampla rede de bondes da época mal atinge a área central da cidade atual. A cidade era de fato radicalmente outra, e sua expansão posterior encontrará outros meios, pois não se soube (não se quis, não foi possível?) fazê-la funcionar com a expansão da rede de bondes elétricos.

Com o estudo se pretendeu uma demonstração geral da pertinência de investir numa cartografia digital geo-histórica em associação com formulações teóricas sobre espaço, sobre cidade nas pesquisas retrospectivas sobre uma realidade social, sobre uma realidade espacial, como no caso é a cidade de São Paulo, na abertura do século $\mathrm{XX}$.

\section{SOBRE OS AUTORES}

FERNANDA PADOVESI FONSECA é professora de Cartografia no Departamento de Geografia da Faculdade de Filosofia, Letras e Ciências Humanas da Universidade de São Paulo (FFLCH/USP).

E-mail: ferpado@gmail.com

EDUARDO DUTENKEFER é mestre em Geografia e doutorando no Programa de Pós-graduação em Geografia Humana da FFLCH/USP.

E-mail: dutenkefer@gmail.com

LUCIANO ZOBOLI é graduando em Geografia na FFLCH/USP.

E-mail: luciano.zoboli@usp.br

JAIME TADEU OLIVA é professor e pesquisador da área de geografia do Instituto de Estudos Brasileiros- IEB/USP

E-mail: jtoliva@gmail.com; jtoliva@usp.br

\section{REFERÊNCIAS BIBLIOGRÁFICAS}

ACKEL, Luiz; CAMPOS, Candido Malta. Antecedentes: a modernização de São Paulo. In: SOMEKH, Nádia; CAMPOS, Cândido Malta (Org.). A cidade que não pode parar: planos urbanísticos de São Paulo no século XX. São Paulo: Mackpesquisa, 2002. 
BRAUDEL, Fernand. A dinâmica do capitalismo. Rio de Janeiro: Rocco, I987.

CAUVIN, Colette. Une methode generale de comparaison cartographique: la regression bidimensionnelle.

Travaux et recherches, Fascicule 4. Strasbourg: UER de Geographie, Universite Louis Pasteur/ERA 2I4 CNRS, I984.

. L'accessibilité intraurbaine: une approche méthodolohique. In: CAUVIN, Colette; REYMOND, Henri; KLEINSCHMAGER, Richard. (Org). L'espace géographique des villes. Paris: Anthropos, I998. . Logiciel de comparaison spatiale Darcy 2.0. Mode d'emploi. Paris: Besançon, Strasbourg, 2009. Disponível em: 〈http://spatial-modelling.info/-Spatial-analysis-tools〉. Acesso em: 6 dez. 2010.

CAUVIN, Colette; ESCOBAR, F.; SERRADJ, A. Cartographie thematique I. Paris: Lavoisier, 2007.

CAUVIN, Colette; LEPETIT, Bernard; REYMOND Henry. Cartes postales: un espace de relationdansla France pré-industrielle. Histoire er mesure, I987, v. 2, n. 3-4. p. 89-пr3. Disponível em: 〈http://www. persee.fr/web/revues/home/prescript/article/hism_0982-I783_I987_num_2_3_I327〉. Acesso em: 20 jun. 2016.

COMMISSÃO GEOGRAPHICA E GEOLOGICA. Planta Geral da Cidade de São Paulo. Memória Urbana: a Grande São Paulo até I940. São Paulo: Arquivo do Estado, Emplasa, Imprensa Oficial, 200I, v. 3. 76 x 62,64 cm. Escala: I:20.000.

DUTENKEFER, Eduardo. Representações do espaço geográfico: mapas dasimétricos, anamorfoses e modelização gráfica. Dissertação (Mestrado em Geografia). Faculdade de Filosofia, Letras e Ciências Humanas - FFLCH da Universidade de São Paulo - USP, 2010.

. Métodos e metodologias para desvendar a acessibilidade do município de São Paulo, 2014 (mimeo.).

ELLIMAN, Paul. Signal Failure. In: ABRAMS, Janet; HALL, Peter (Ed.). Else/where: mapping new cartographies of networks and territories. Minneapolis: University of Minnesota Press, MN, 2006, p. I66-I75.

FONSECA, Fernanda Padovesi. A inflexibilidade do espaço cartográfico, uma questão para a geografia: análise das discussões sobre o papel da cartografia. Tese (Doutorado em Geografia). Faculdade de Filosofia, Letras e Ciências Humanas - FFLCH da Universidade de São Paulo - USP, 2004.

GOUVÊA, José P. Neves. A produção do espaço de São Paulo através de suas representações cartográficas. Dissertação (Mestrado em Tecnologia da Arquitetura). Faculdade de Arquitetura e Urbanismo - FAU da Universidade de São Paulo - USP, 2010.

GRATALOUP, Christian. Géohistorie. in: LÉVY, Jacques; LUSSAULT, Michel (Org.). Dictionnaire de la geographie et de l'espace des sociétés. Paris: Belin, 2003.

GUERMOND, Yves. Géomatique. In: LÉVY, Jacques; LUSSAULT, Michel (Org.). Dictionnaire de la geographie et de l'espace des sociétés. Paris: Belin, 2003, p. 402.

HARLEY, John Brian. A nova história da cartografia. O Correio da Unesco (mapas e cartógrafos), Brasil, ano I9, n. 8, ago. I99I, p. 4-9.

INFORMATIVO AHM. Arquivo Histórico Municipal Washington Luís. São Paulo antigo: plantas da cidade, n. 20, set.-out. 2008. Disponível em: 〈http://www.arquiamigos.org.br/info/info2o/index.html\#topo >. Acesso em: 20 jun. 2016.

JENNY, Bernhard; WEBER, Adrian; HUERNI, Lorenz. Visualizing the planimetric accuracy of historical maps with MapAnalyst. Cartographica: The International Journal for Geographic Information and Geovisualization, v. 42, issue I, 2007, p. 89-94.

KAKO, Iara Sakitani. O papel dos trilhos na estruturação territorial da cidade de São Paulo de I867 a I930. Tese (Doutorado em Geografia Humana). Faculdade de Filosofia, Letras e Ciências Humanas - FFLCH da Universidade de São Paulo - USP, 20I3).

LÉVY, Jacques. Le tournant géographique - penser l'espace pour lire le monde. Paris: Belin, I999. 400 p. (Mappemonde 8). 
LEVY, Jacques. Os novos espaços da mobilidade. GEOgraphia, Revista da Pós-graduação em Geografia da Universidade Federal Fluminense - UFF, v. 3, n. 6. Niterói/ RJ, UFF/EGG, 2002, p. 7-I7. Disponível em: 〈http://www.uff.br/geographia/ojs/index.php/geographia/article/viewFile/62/60〉. Acesso em: II jul. 20I4.

LÉVY, Jacques. Ville. In: LÉVY, Jacques; Lussault Michel (Org.). Dictionnaire de la geographie et de l'espace des sociétés. Paris: Belin, 2003.

LÉVY, Jacques. Métrique. In: LÉVY, Jacques; LUSSAULT, Michel (Org.). Dictionnaire de la géographie et de l'espace des sociétés. Paris: Belin, 2003, p. 607-609.

LÉVY, Jacques; LUSSAULT, M. Espace. In: LÉVY, Jacques; LUSSAULT, Michel (Org.). Dicitionnaire de la geographie et de l'espace des societes. Paris: Belin, 2003. p. 325-333.

LOGICIEL de transformation cartographique unipolaire IsoDistAngle. Conception: Colette Cauvin; Réalisation: Gilles Vuidel, Strabourg, 20I3. Disponível em: 〈http://thema.univ-fcomte.fr/IsoDistAngle〉. Acesso: 2 abr. 2014

LUSSAULT, Michel. L'homme spatial: la construction sociale de l'espace humain. Paris: Seuil, 2007.364 p. MONGIN, Olivier. A condição urbana: a cidade na era da globalização. São Paulo: Estação Liberdade, 2009. $344 \mathrm{p}$.

MORSE, Richard M. Formação histórica de São Paulo (de comunidade a metrópole). São Paulo: Difel, I970.

OLIVA, Jaime Tadeu. A cidade como ator social: a força da urbanidade. In: ALESSANDRI CARLOS, Ana Fani; LEMOS, Amália Inês Geraiges (Org.). Dilemas urbanos: novas abordagens sobre a cidade. São Paulo: Contexto, 2003, p. 73-80.

PAULA, E. S. de. A segunda fundação de São Paulo. Da pequena cidade à grande metrópole de hoje. Revista de História - USP, n. I7, I954, p. I67-I79.

PASSOS, Maria L. Perrone; EMÍDIO, Teresa. Desenhando São Paulo: mapas e literatura - I877-I954. São Paulo: Senac/Imprensa Oficial, 2009.

PINTO, Alfredo Moreira. A cidade de São Paulo em I900. São Paulo: Governo do Estado de São Paulo, I979

PREFEITURA DE SÃO PAULO. Histórico demográfico do município de São Paulo. - Tabelas . Disponível em: 〈http://smdu.prefeitura.sp.gov.br/historico_demografico/tabelas.php〉. Acesso em: 20 jun. 2016.

REIS FILHO, Nestor Goulart. São Paulo: vila cidade metrópole. São Paulo: Prefeitura de São Paulo, 2004

SIMONI, Lucia Noemia. A planta da cidade de São Paulo de I897: uma cartografia da cidade existente ou da cidade futura? In: SIMPÓSIO LUSO-BRASILEIRO DE CARTOGRAFIA HISTÓRICA, 3., 2009, Ouro Preto. Anais... Disponível em: <https://www.ufmg.br/rededemuseus/crch/simoni_a-planta-da-cidadede-sao-paulo-de-I897.pdf >. Acesso em: 20 jun. 2016.

STIEL, Waldemar Correa. História dos transportes coletivos em São Paulo. São Paulo: McGraw-Hill do Brasil, I978.

TOBLER, Waldo. The development of analytical cartography: a personal note. Disponível em: <http:// www.geog.ucsb.edu/ kclarke/GeographyI28/Tobler200o.pdf $>$. Acesso em: I6 set. 20I3. 20 jun. 2016.

TOLEDO, Roberto P. A capital da vertigem: uma história de São Paulo de I900 a I954. Rio de Janeiro: Objetiva, 2015. 